\title{
A review of the Afrotropical Rhyssinae (Hymenoptera: Ichneumonidae) with the descriptions of five new species
}

\author{
Pascal ROUSSE ${ }^{1,2,4, *} \&$ Simon VAN NOORT ${ }^{1,3,5}$ \\ ${ }^{1}$ Natural History Department, Iziko South African Museum, PO Box 61, \\ Cape Town 8000, South Africa \\ ${ }^{2}$ Stellenbosch University, Department of Botany and Zoology, Evolutionary Genomics Group, \\ Private Bag X1, Stellenbosch 7602, South Africa \\ ${ }^{3}$ Department of Biological Sciences, University of Cape Town, Private Bag, \\ Rondebosch 7701, South Africa \\ *Corresponding author: rousse.pascal@wanadoo.fr \\ ${ }^{4}$ urn:Isid:zoobank.org:author:B06C2640-700A-429B-AA2F-1BE09251C845 \\ ${ }^{5}$ urn:1sid:zoobank.org:author:7CCD166F-F1FA-43DA-B582-4E84EAF59AD1
}

\begin{abstract}
The Afrotropical Rhyssinae are reviewed. A total of 12 species are reported from the region, including five new species: Epirhyssa brianfisheri sp. nov., E. gavinbroadi sp. nov., E. shaka sp. nov., E. villemantae sp. nov. and $E$. tombeaodiba sp. nov. The generic status of $E$. brianfisheri sp. nov. is discussed since this species could also be considered to be an extra-limital Triancyra species, emphasizing the putative paraphyletic status of Epirhyssa. Epirhyssa ghesquierei Seyrig, 1937, E. overlaeti Seyrig, 1937 and $E$. uelensis Benoit, 1951 are newly reported from Cameroon. We provide illustrated diagnoses and identification notes. Finally, we discuss the apparent scarcity of African rhyssines compared to other regions.
\end{abstract}

Keywords. Parasitoid wasps, systematics, taxonomy, Africa, descriptions, identification keys

Rousse P. \& Van Noort S. 2014. A review of the Afrotropical Rhyssinae (Hymenoptera: Ichneumonidae) with the descriptions of five new species. European Journal of Taxonomy 91: 1-42. http://dx.doi.org/10.5852/ejt.2014.91

\section{Introduction}

In many respects, Rhyssinae are atypical amongst Ichneumonidae. First, unlike most ichneumonids, they are rather well known to the public because of their spectacular habitus. The subfamily includes some of the largest species of ichneumonid wasps, exhibiting often striking color patterns. They also have very long ovipositors used to access their wood-boring hosts. For example, species of Megarhyssa Ashmead, 1900 often have an ovipositor that has a length of more than $20 \mathrm{~cm}, 3 \mathrm{x}$ longer than the entire body, i.e., relatively and absolutely some of the longest known in insects (Townes 1975). They are readily identifiable: the upper mandibular tooth is truncate and chisel-shaped, the mesoscutum is flattened and crossed by deep transverse rugosities, and the last tergite of the female bears an apical horn-like projection. Traditionally included as a tribe within Pimplinae, they were then considered as a 
separate monophyletic subfamily, mostly defined by the above autapomorphies, within the pimpliforme subfamily group (Gauld 1991; Wahl \& Gauld 1998).

Second, their diversification history appears to be an exception to the general rule that most taxa in the tree of life arose in tropical areas and then diversified into the temperate areas (Jansson et al. 2013). The genus Rhyssa, considered to be the most basal lineage of Rhyssinae, is almost exclusively Holarctic, whereas the more derived genera are primarily or exclusively tropical; the origin of other pimpliform subfamilies (e.g., Diacritinae, Poemeniinae, Acaenitinae) was hypothesized to be in the Northern Hemisphere for similar reasons (Wahl \& Gauld 1998). However, their actual diversity in the tropics, especially in the Neotropical and Afrotropical regions, appears to have been previously greatly underestimated (Quicke 2012; Veijalainen et al. 2013).

The generic composition of Rhyssinae in tropical and temperate regions may be correctly assessed by long-term sampling efforts. Rhyssinae are indeed exceptional for a third reason: due to their conspicuous habitus, their moderate diversity, and their potential economic impact for biocontrol of wood-boring pests, they received significantly more attention than most of the other ichneumonid subfamilies. Available reviews cover the following regions: Oriental and Australasian (Baltazar 1961; Kamath \& Gupta 1972; Sheng \& Sun 2010), Nearctic (Townes et al. 1960), Neotropical (Porter 1978; Gauld 1991; Gauld et al.1997), and Palaearctic (Horstmann 2002; Kasparyan \& Khalaim 2007). They total about 250 species in eight genera (Yu et al. 2012). Nearly half of these species belong to the circumtropical genus Epirhyssa Cresson, 1865. All host records are coleopteran or symphytan larvae (Yu et al. 2012). They have also been reported to develop as facultative hyperparasitoids of other Symphyta parasitoids (Hanson 1939), and are able to oviposit and develop on many surrogate hosts (Spradbery 1968). Indeed, as idiobiont ectoparasitoids, the entire host selection process is only conditioned by what they can locate, led mostly by chemical and mechanical stimuli (Spradbery 1970): any potential host they eventually find is thus reduced to a mere "bag of meat" without any immune response to deal with, making the host range potentially broader.

In accordance with the general rule for Ichneumonidae, their diversity in the Afrotropical region has been poorly investigated. To date, only seven species have been reported from the region, of which six belong to Epirhyssa (Yu et al. 2012). This is a relatively poor richness in comparison with the 48 currently described Neotropical species (all Epirhyssa), to which many others have still to be added (Sääksjärvi et al. 2004), and the 140 Oriental and/or Australasian species (52 Epirhyssa). Rhyssinae are expected to be most species-rich in lowland tropical rainforests (Gauld 1991), and hence these seven Afrotropical species reflect the poor knowledge we have of the subfamily on this continent. This paper therefore aims firstly to review the currently known species, by gathering, translating and updating their descriptions (Seyrig 1937; Benoit 1951, 1952), secondly to add five new species from undetermined material housed in African and European museums, and then to provide proper identification and description tools for the expected numerous Rhyssinae species still to be collected in the Afrotropical Region. The scarcity of available specimens is discussed.

\section{Material and Methods}

\section{Photographs}

Specimens were point mounted on black, acid-free card for examination (using a Leica M205C stereo microscope with a LED light source), photography and long-term preservation. Images were taken using the EntoVision ${ }^{\circledR}$ multiple-focus imaging system. This system combines a Leica ${ }^{\circledR}$ M16 microscope with a JVC ${ }^{\circ}$ KY-75U 3-CCD digital video camera attached that feeds image data to a notebook computer. The program Cartograph ${ }^{\circledR} 5.6 .0$ was then used to merge an image series (representing typically 10 15 focal planes) into a single in-focus image. Lighting was achieved using techniques summarized in 
Buffington et al. (2005), Kerr et al. (2008) and Buffington \& Gates (2009). All images presented in this paper are available at http://www.waspweb.org

\section{List of Depositories}

BMNH $=$ Natural History Museum, London, UK (Gavin Broad)

MNHN = Muséum National d'Histoire Naturelle, Paris, France (Claire Villemant)

MRAC = Muséum Royal de l'Afrique Centrale, Tervueren, Belgium (Eliane de Coninck)

NMSA $=$ KwaZulu-Natal Museum, Pietermaritzburg, South Africa (Burgert Muller)

SAMC = Iziko South African Museum, Cape Town, South Africa (Simon van Noort)

\section{Nomenclature and abbreviations}

Morphological terminology follows Wahl \& Sharkey (1993), but wing venation nomenclature follows Gauld (1991). Most morphological terms are also defined on the HymAToL website (http://www. hymatol.org) and HAO website (http://portal.hymao.org/projects/32/public/ontology/). If not indicated otherwise, all geographical records are extracted from the Taxapad database (Yu et al. 2012). The following morphometric abbreviations are used:

$\mathrm{B}=$ body length, from toruli to metasomal apex ( $\mathrm{mm})$

A = antenna length, from base of scape to flagellar apex ( $\mathrm{mm})$

$\mathrm{F}=$ fore wing length, from tegula to wing apex $(\mathrm{mm})$

$\mathrm{CT}=$ clypeus transversality index (maximum width of clypeus / median height)

$\mathrm{ML}=$ malar line index (malar line / basal mandibular width)

POL $=$ post-ocellar index (shortest distance between posterior ocelli / ocellus maximal diameter)

$\mathrm{OOL}=$ oculo-ocellar index (shortest distance between eye and posterior ocellus / ocellus maximum diameter)

$\mathrm{Fl}_{\mathrm{n}} \quad=$ length index of flagellomere $\mathrm{n}$ (length / width of flagellomere $\mathrm{n}$ )

$\mathrm{T} 1=$ tergite 1 elongation index, (median length of tergite $1 /$ apical width (applies to female only if not otherwise specified))

OT = ovipositor sheath-tibia index (length of ovipositor sheath / length of hind tibia)

The first three measurements (absolute measures) were measured on all specimens in the type series, with data for the primary type reported separately in brackets if necessary. The relative indices were measured on the primary type specimen only.

\section{Results}

Five new species were found in the undetermined material from BMNH, NMSA and SAMC. The key to and the descriptions of all species are provided below. Additional online dichotomous and matrix keys are available at www.waspweb.org. 


\section{Key to species}

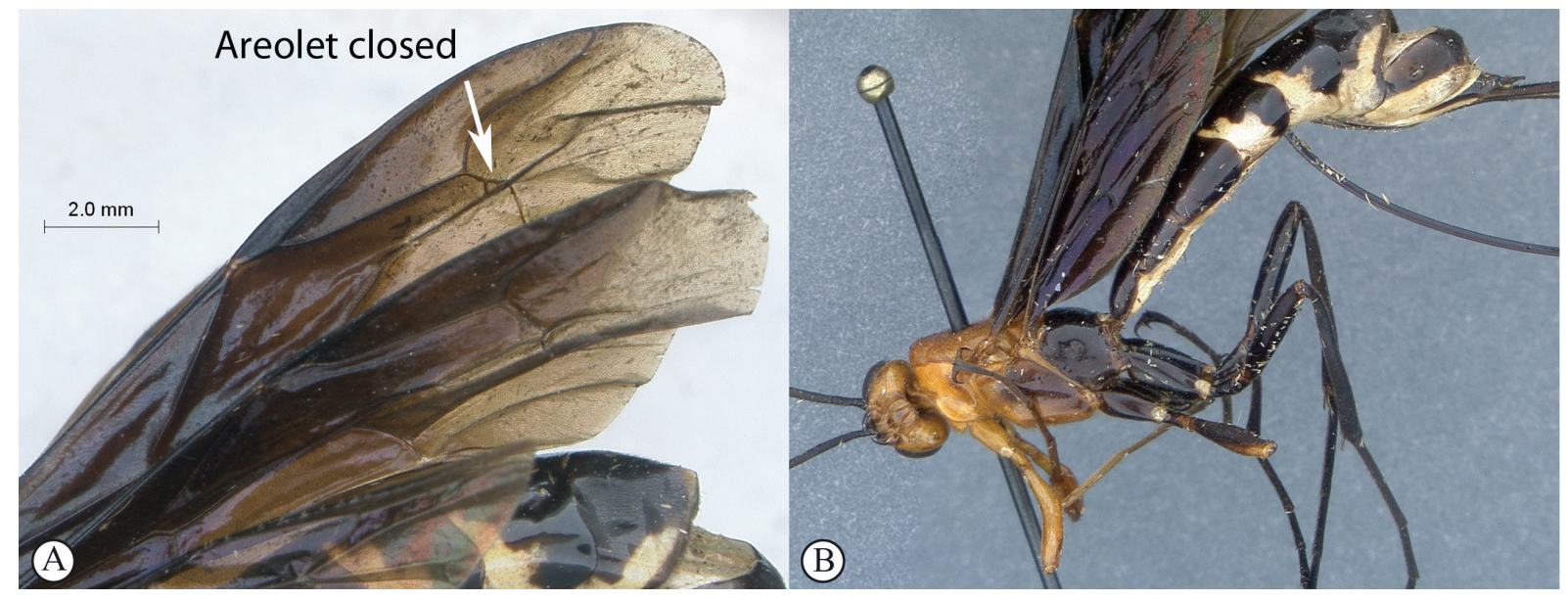

1. Fore wing with areolet closed, triangular and strongly petiolate (A); body orange and dark brown, wings dark brown (B); tropical Africa ........................Megarhyssa babaulti Seyrig, 1937
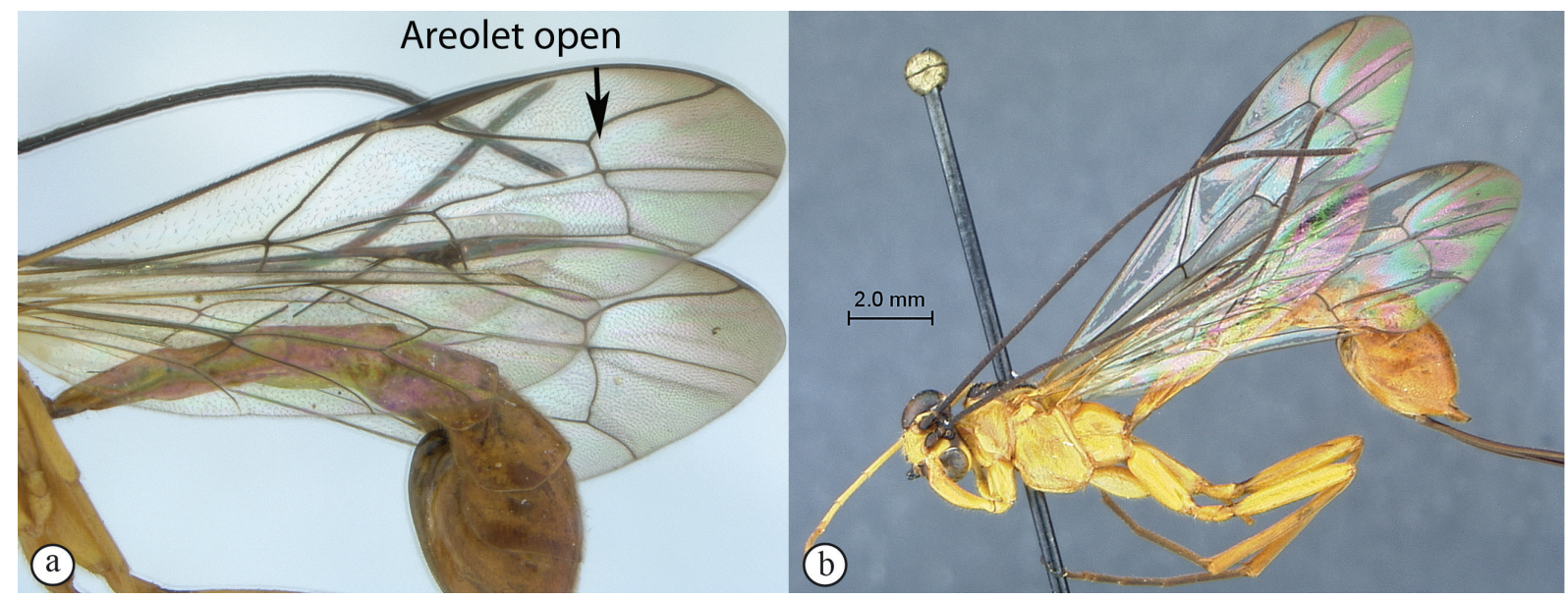

- Fore wing with areolet open (a); body and wings colorations variable but usually wings hyaline and body yellow interspersed with black markings (b) 2 (Epirhyssa)

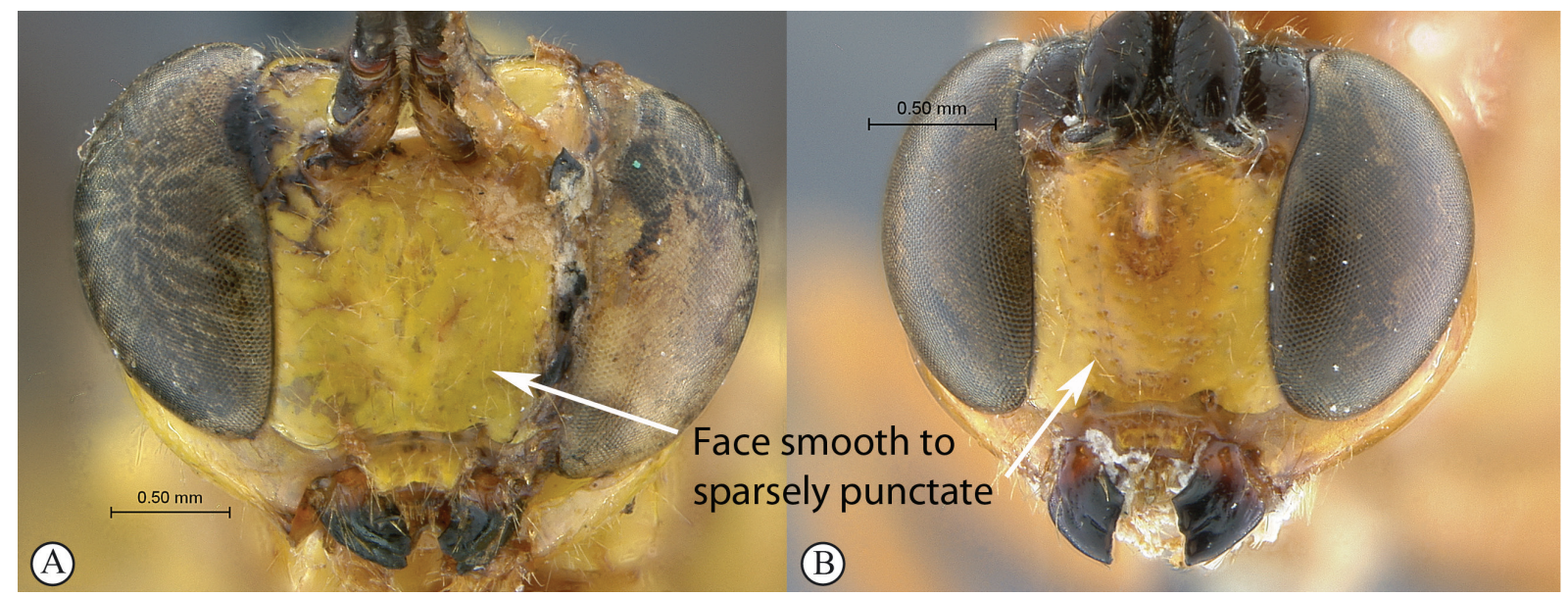

2. Face smooth to sparsely punctate (A-B), without transverse rugosities 


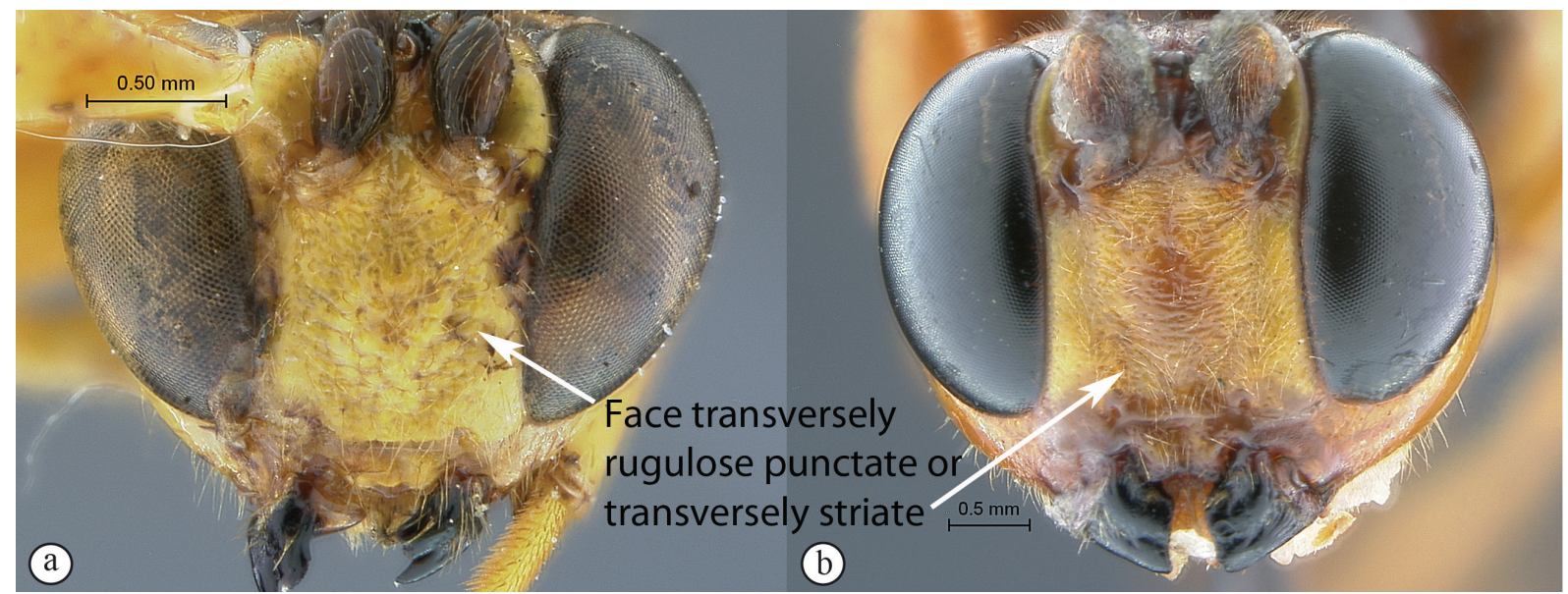

- Face transversely rugulose punctate or transversely striate (a-b)

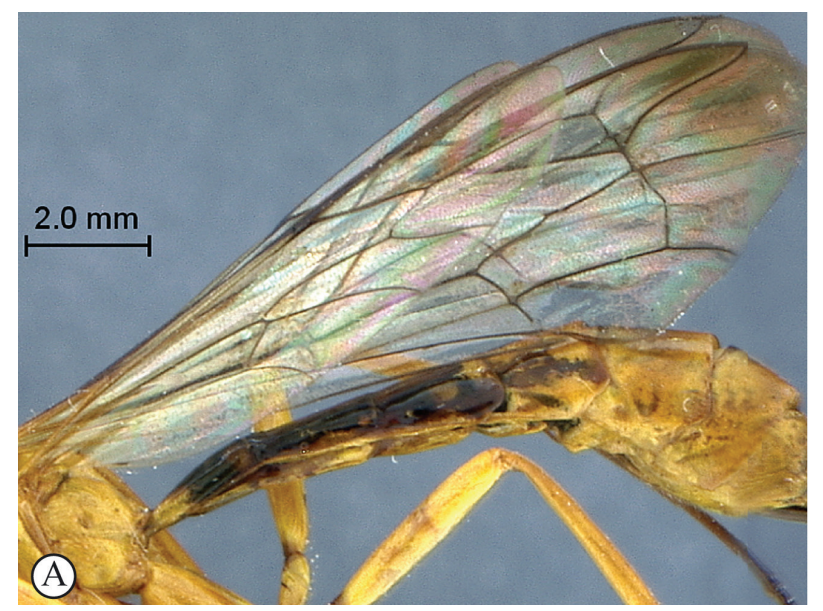

3. Wings hyaline, fore wing slightly infuscate apically (A); Madagascar .....E. migratoria Seyrig, 1932

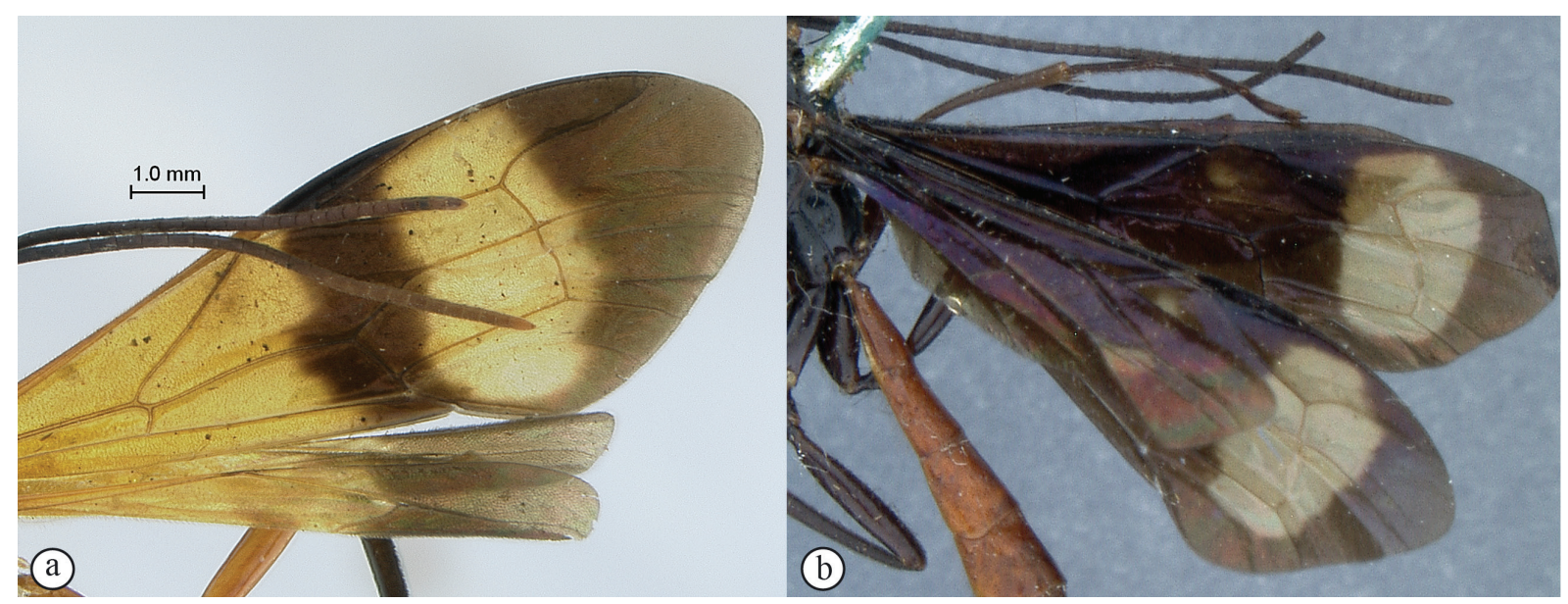

- Wings with dark patterns, yellowish to black (a, b); tropical Africa 


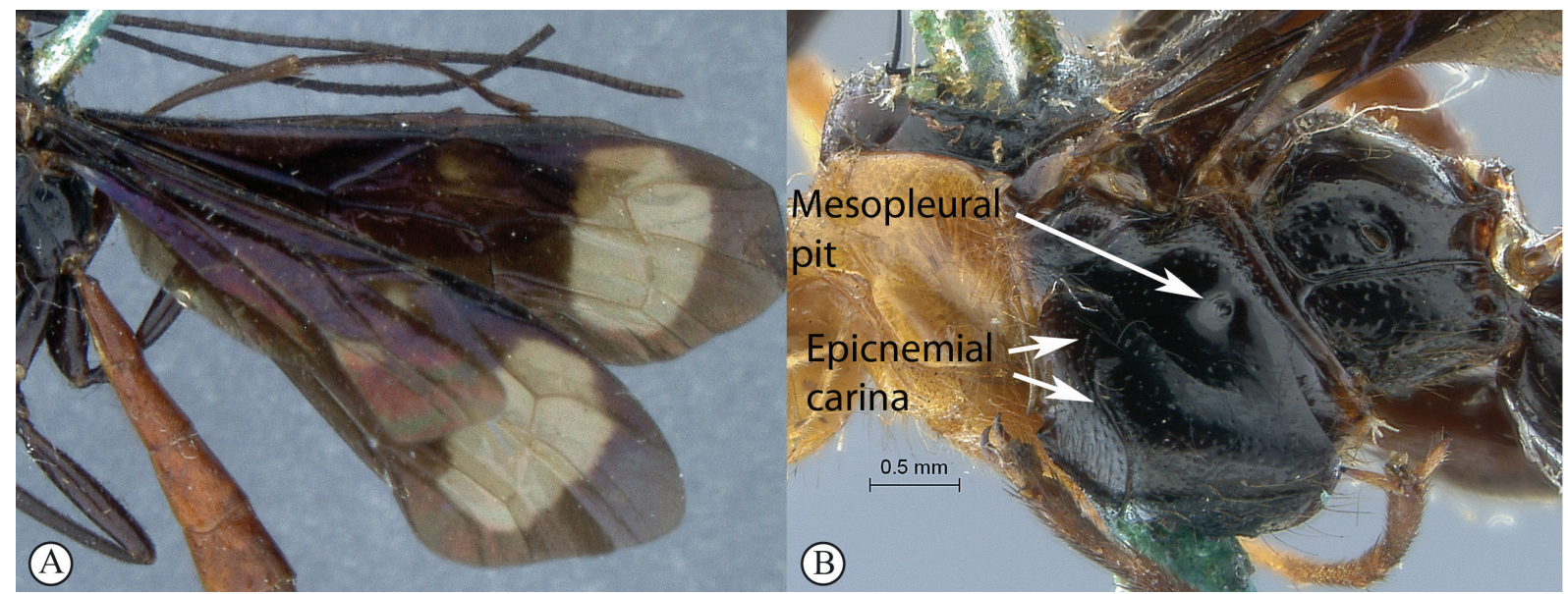

4. Wings blackish with subapical lighter patch (A); epicnemial carina reaching level of mesopleural pit (B)

E. villemantae sp. nov.

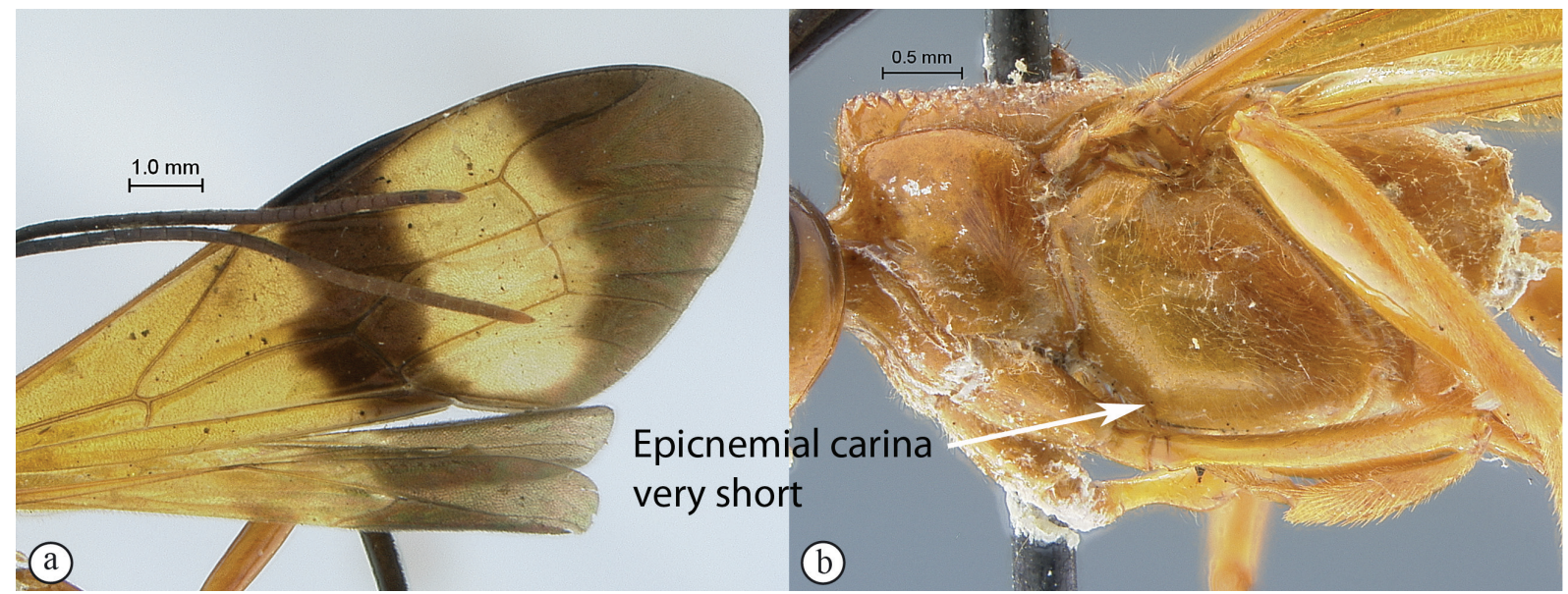

- Wings yellowish with apex blackish and an additional subapical transverse blackish band on fore wing (a); epicnemial carina very short, hardly extending onto mesopleuron (b)

E. maynei Benoit, 1952

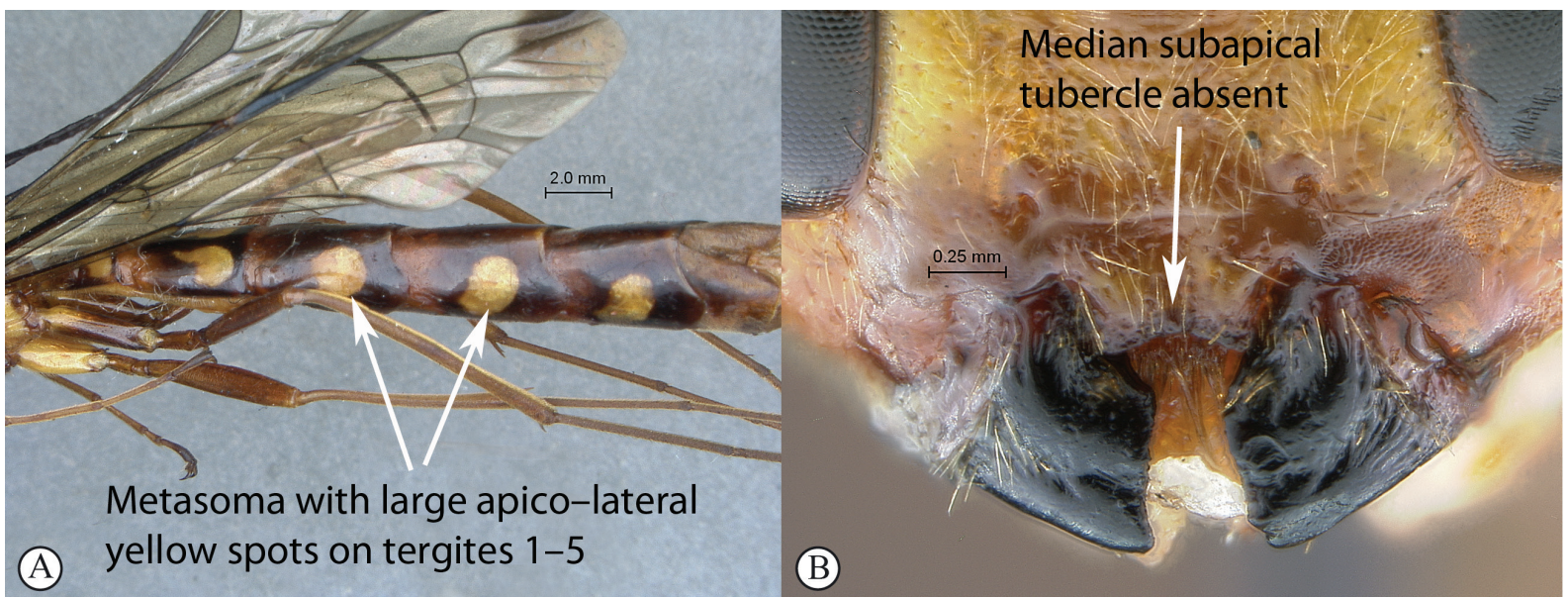

5. Metasoma with large apico-lateral yellow spots on tergites 1-5 (A); clypeus without median subapical tubercle (B); body and ovipositor large to very large $(\mathrm{B}>25 \mathrm{~mm}$; OT $>6)$.....E. overlaeti Seyrig, 1937 


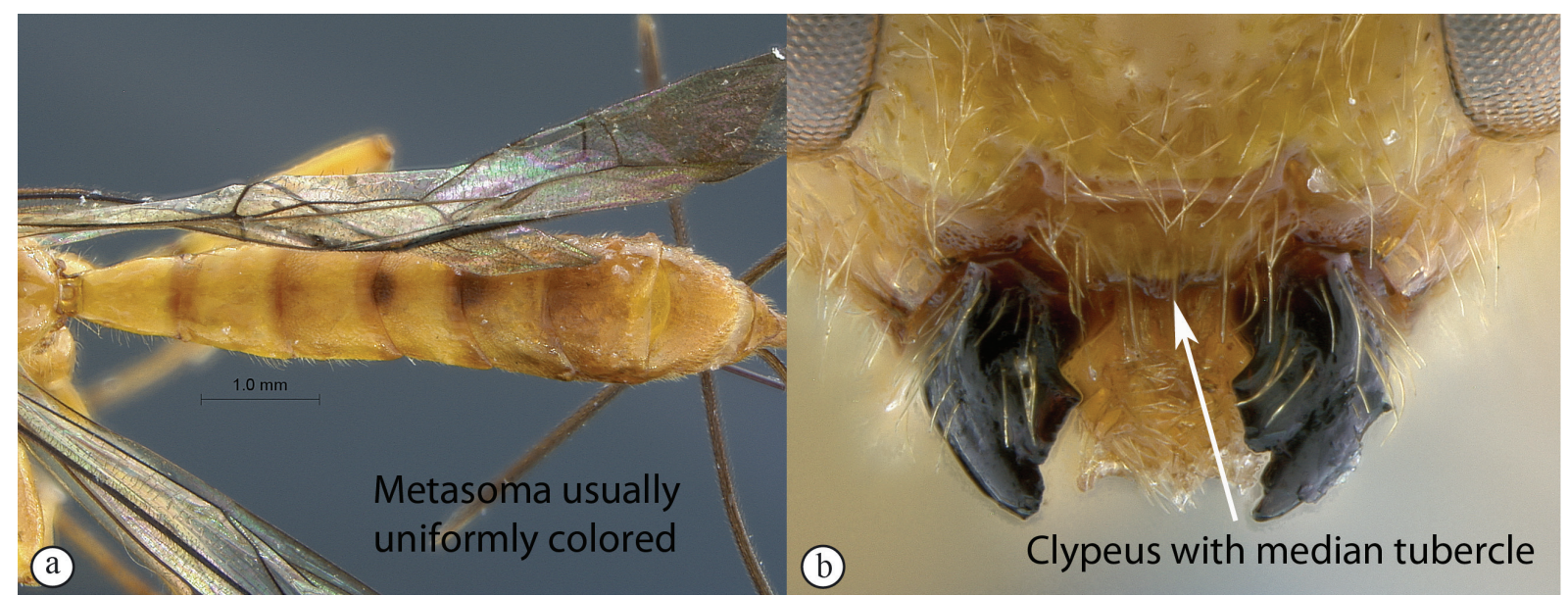

- Metasoma usually uniformly colored (a); clypeus with a distinct subapical tubercle (b); body and

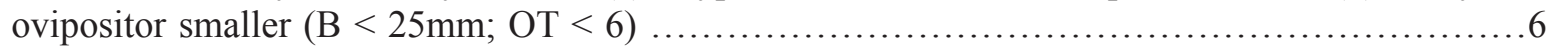

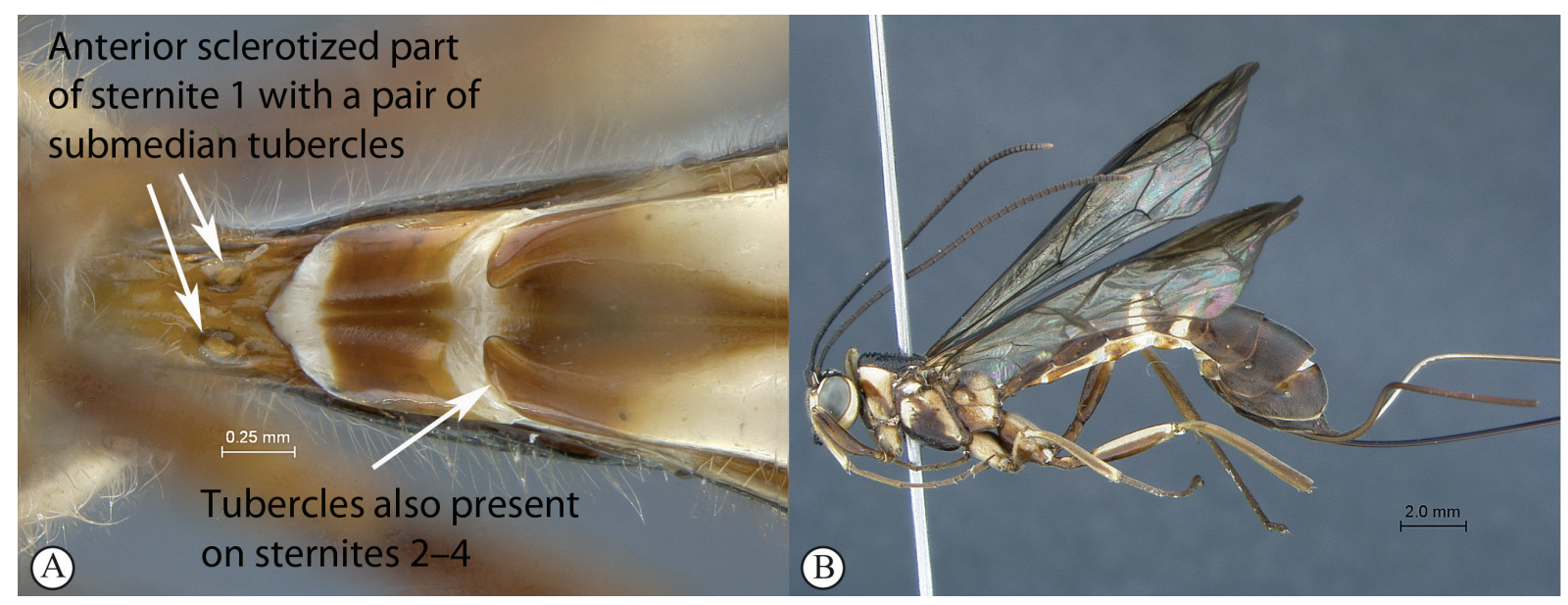

6. Anterior sclerotized part of sternite 1 with a pair of submedian tubercles, tubercles also present on sternites 2-4 (A); general coloration dark testaceous to black interspersed with pale yellow (B) ......

..E. brianfisheri sp. nov.

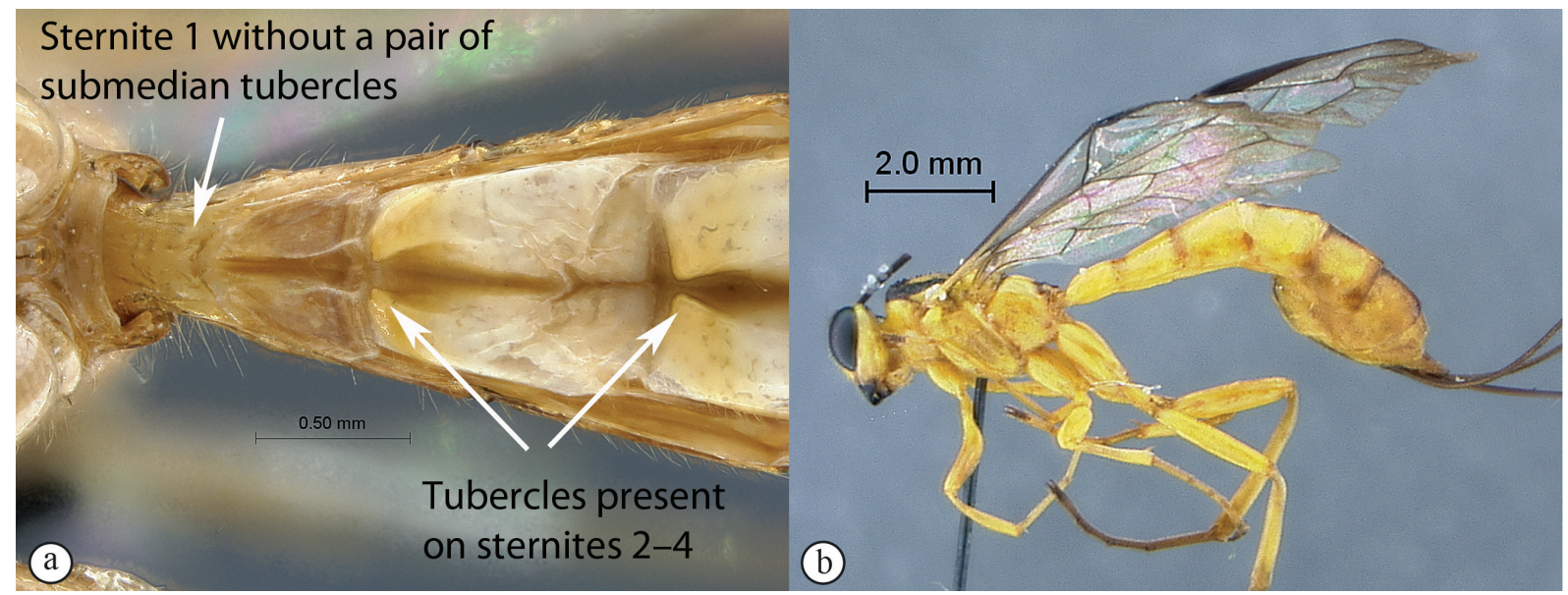

- Sternite 1 without a pair of submedian tubercles, tubercles present on sternites 2-4 only (a); general coloration pale to striking yellow with isolated black markings (b) 


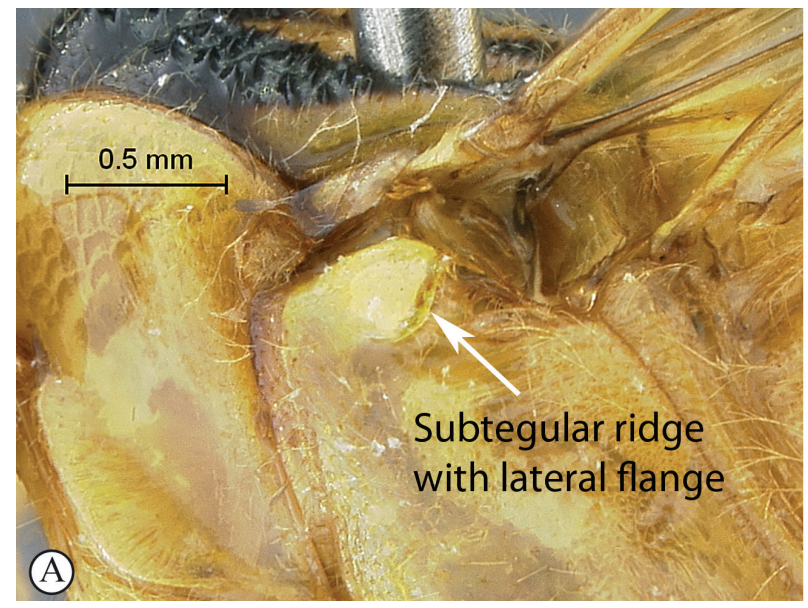

7. Apex of subtegular ridge concave, laterally flanged (A)

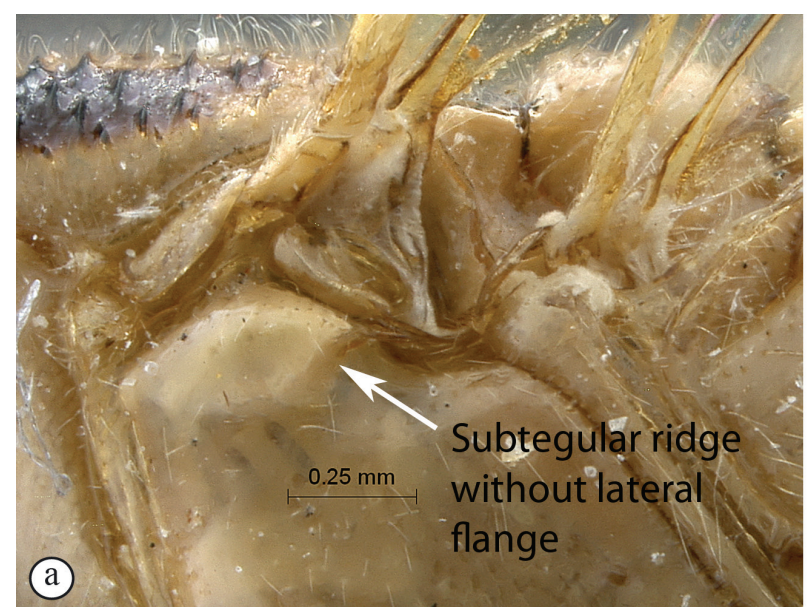

- Apex of subtegular ridge convex, without lateral flange (a) .9

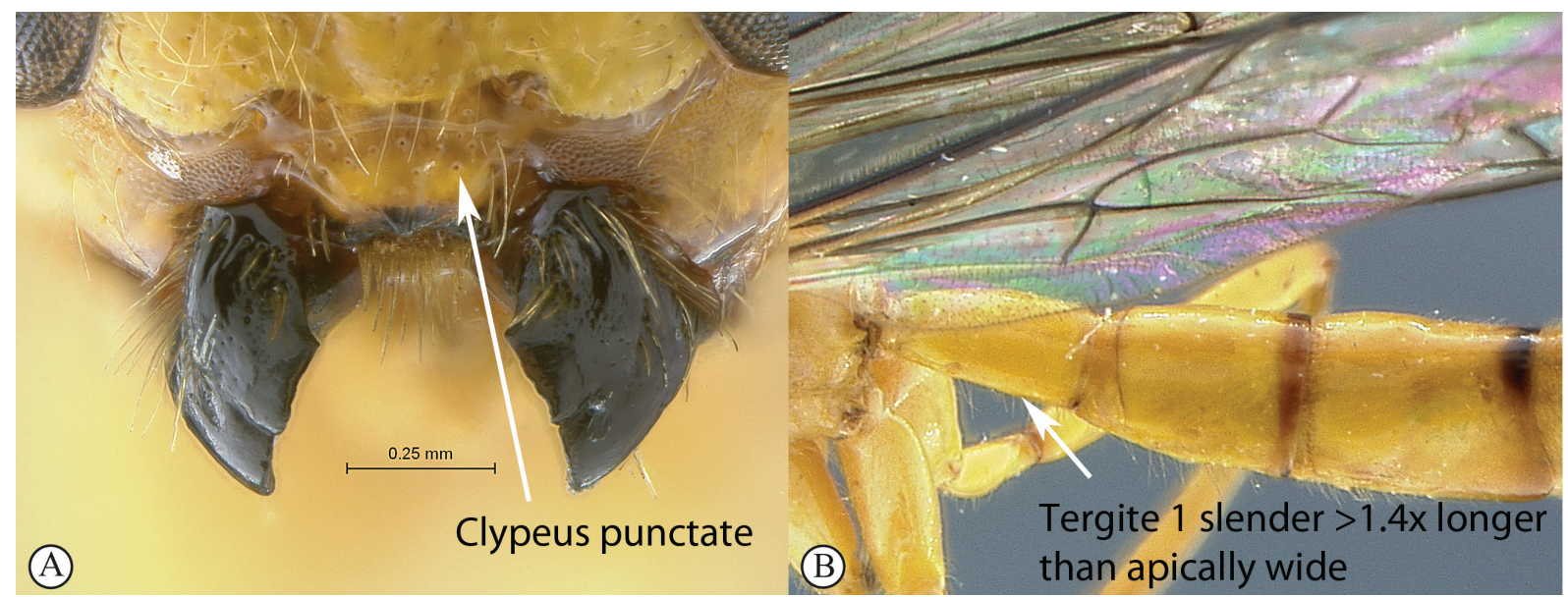

8. Clypeus punctate (A); tergite 1 of female slender, more than $1.4 \mathrm{x}$ longer than apically wide (B) E. gavinbroadi sp. nov. 


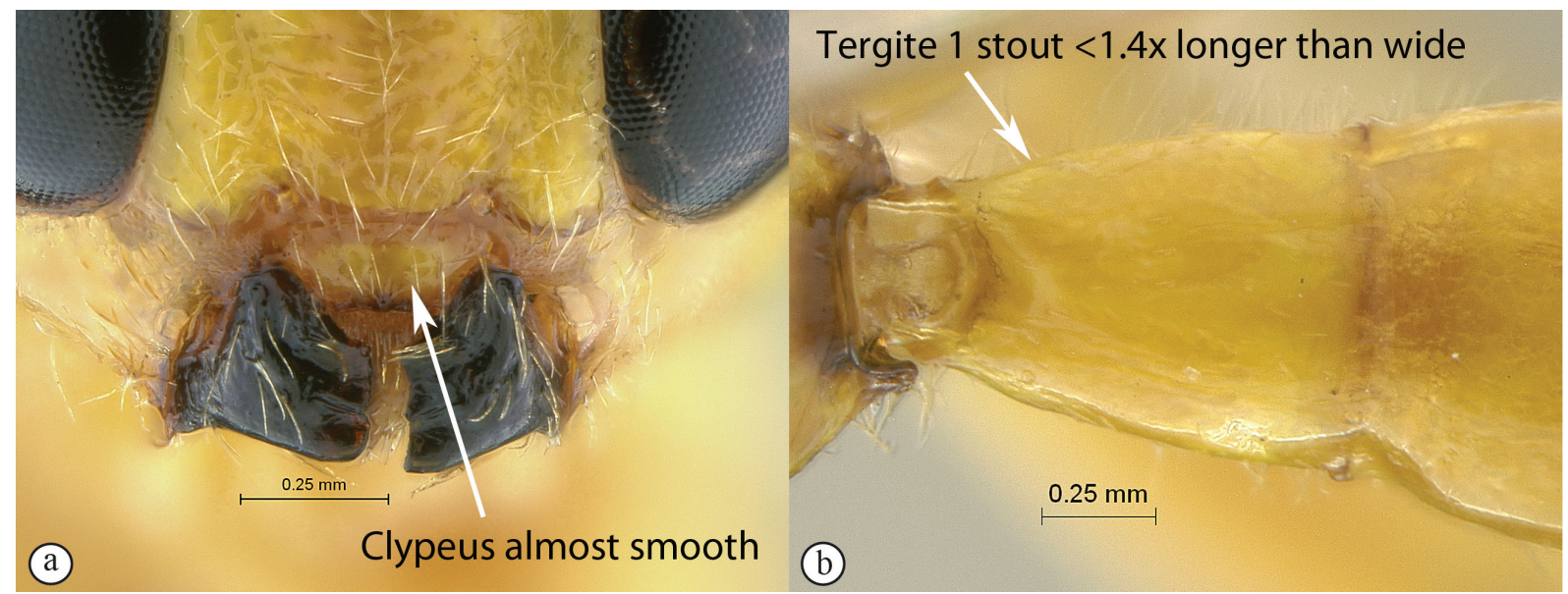

- Clypeus almost smooth, hardly sculptured (a); tergite 1 of female stout, less than $1.4 \mathrm{x}$ longer than wide (b) E. uelensis Benoit, 1951

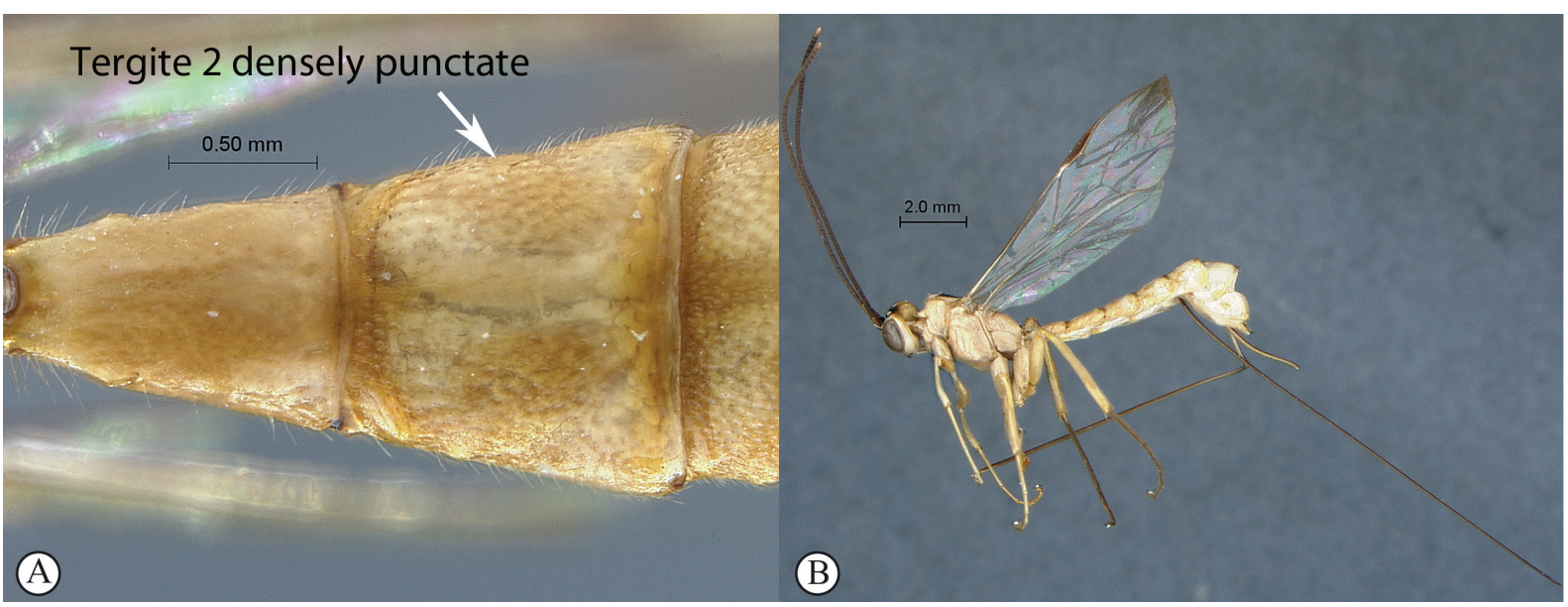

9. Tergite 2 densely punctate over its entire surface and tergite 1 more than $1.5 x$ longer than apically wide (A); general coloration pale yellow (B); Southern Africa

E. shaka sp. nov.

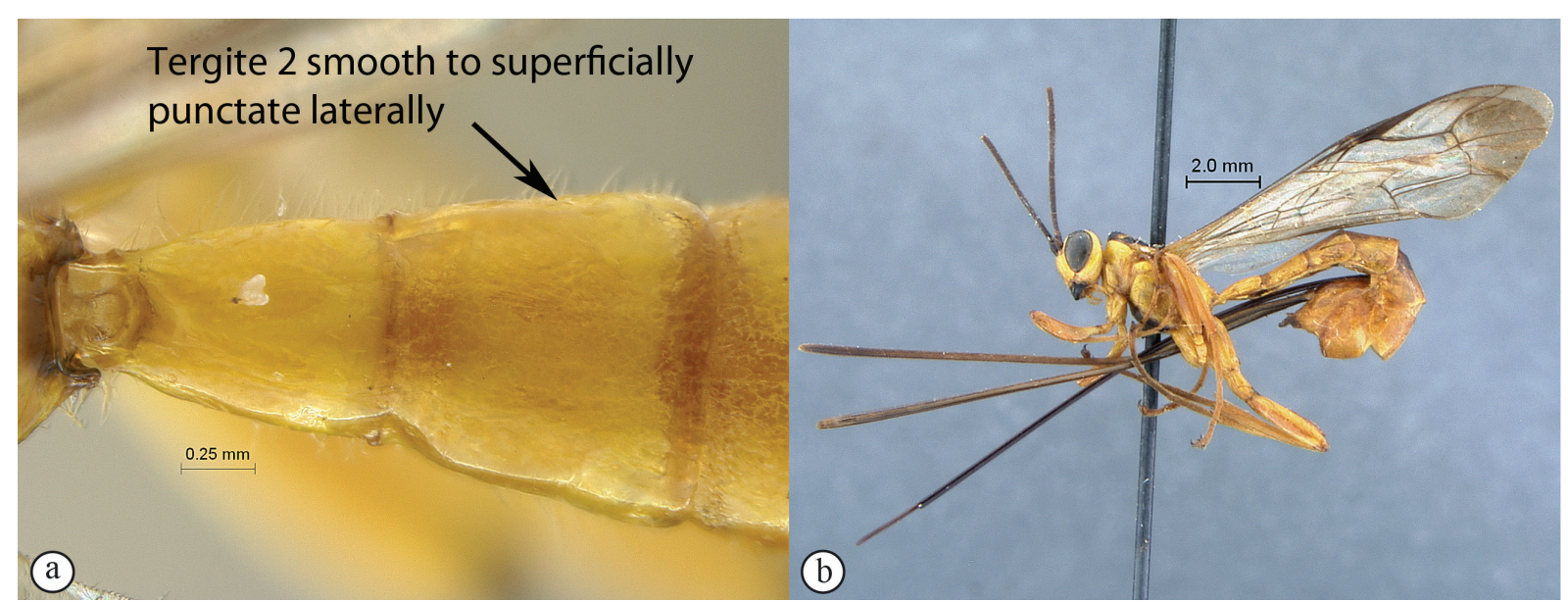

- Tergite 2 smooth to superficially punctate laterally (a), if ambiguous (some E. tombeaodiba) then tergite 1 stouter, less than $1.5 x$ longer than apically wide; general coloration bright yellow (b); tropical Africa 

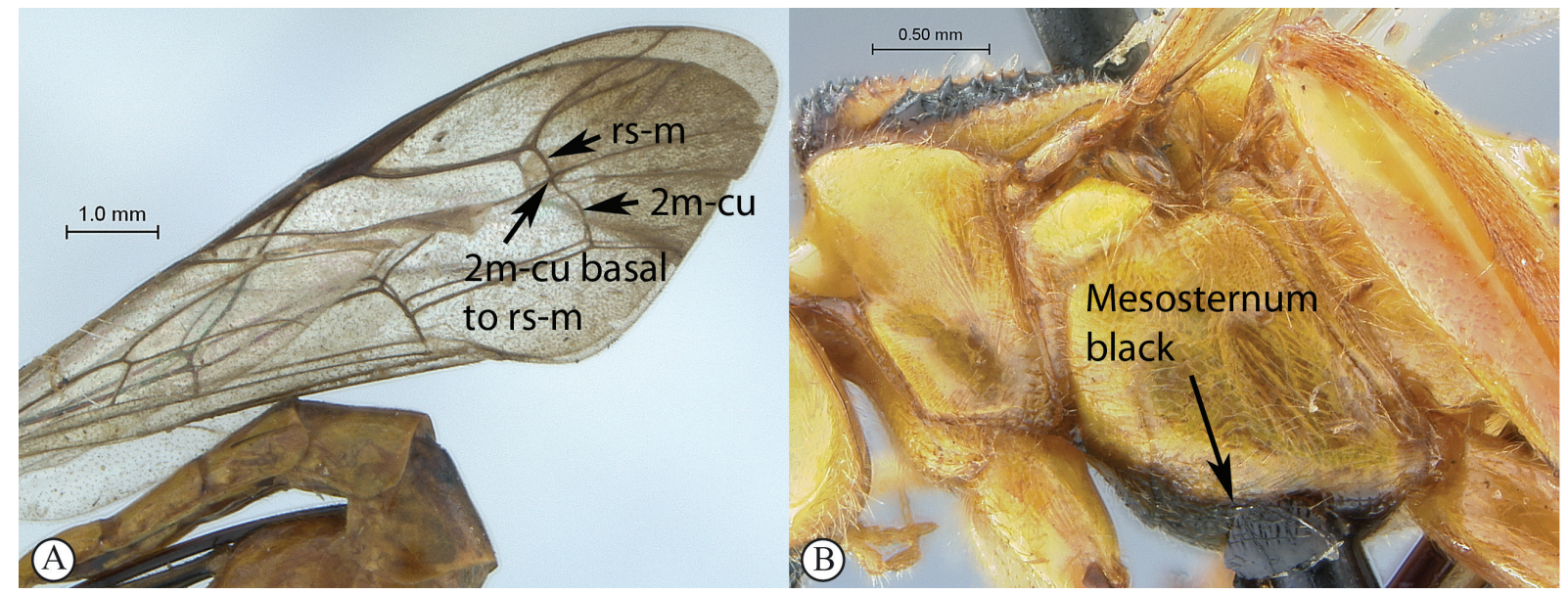

10. Fore wing with $2 \mathrm{~m}-\mathrm{cu}$ basal to $\mathrm{rs}-\mathrm{m}(\mathrm{A})$; mesosternum black (B)

E. leroyi Benoit, 1951
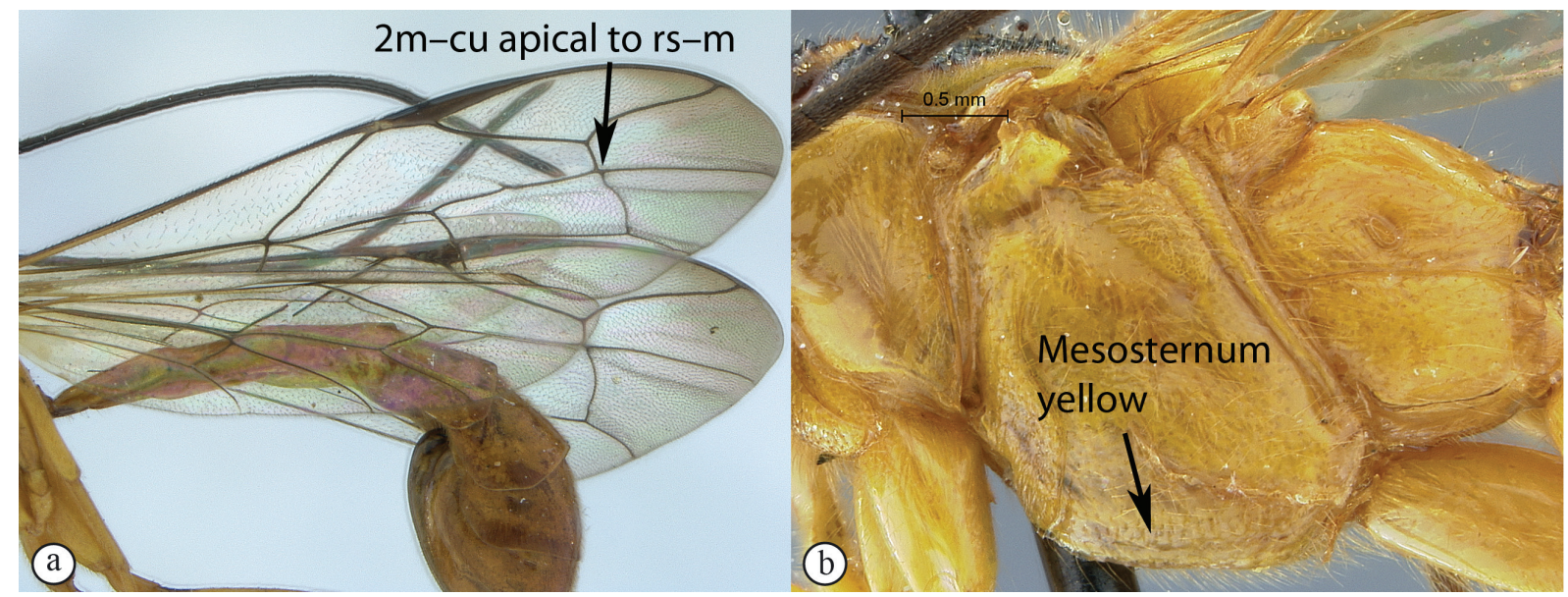

- Fore wing with $2 \mathrm{~m}-\mathrm{cu}$ apical to rs-m (a); mesosternum yellow (b) ......................11

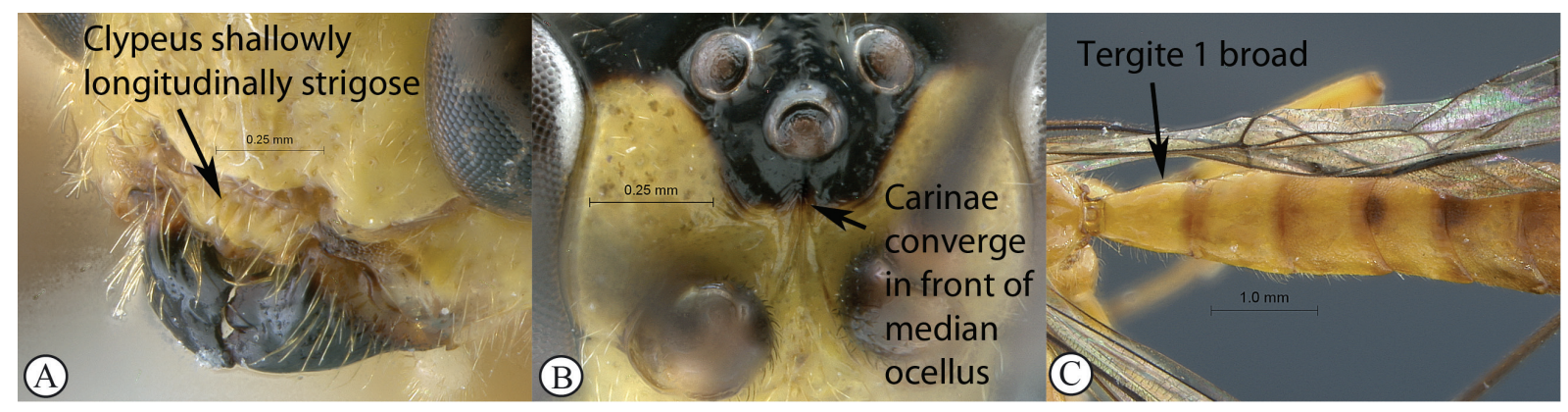

11. Clypeus shallowly longitudinally strigose (A); frons with two medial carinae converging in front of median ocellus (B); tergite 1 of female stout, less than $1.4 x$ longer than apically wide (C) ........... 


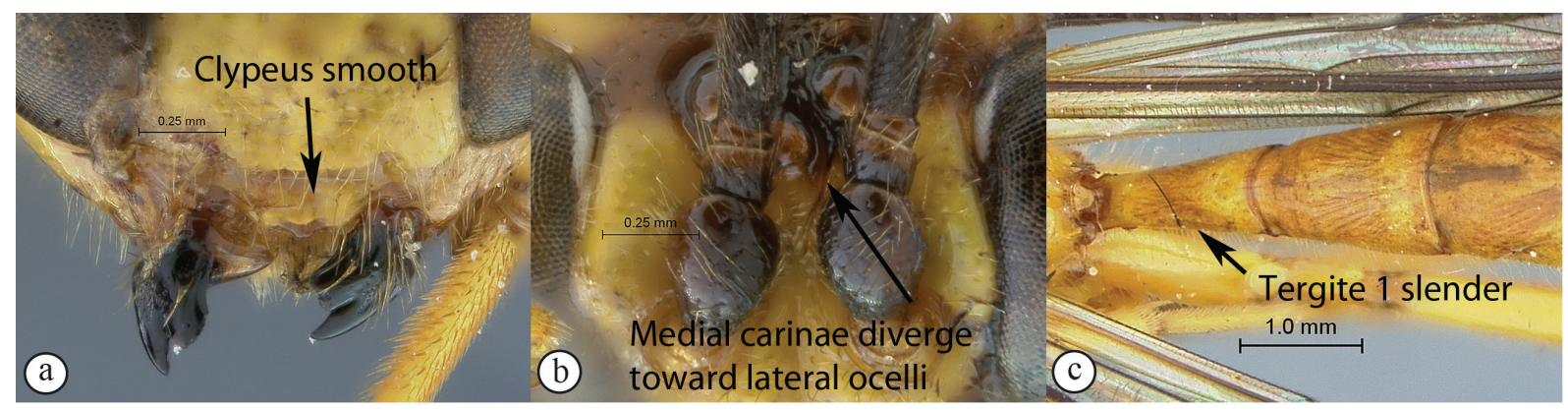

- Clypeus smooth (a); frons with two submedian carinae, diverging on upper frons toward lateral ocelli (b); tergite 1 of female slender, more than $1.4 \mathrm{x}$ longer than apically wide (c) E. ghesquierei Benoit, 1951

\section{Taxonomic descriptions}

Class Hexapoda Blainville, 1816

Order Hymenoptera Linnaeus, 1758

Suborder Apocrita Latreille, 1810

Superfamily Ichneumonoidea Latreille, 1802

Family Ichneumonidae Latreille, 1802

Subfamily Rhyssinae Morley, 1913

Genus Epirhyssa Cresson, 1865

Hierax Tosquinet, 1903: 255.

Rhyssonota Kriechbaumer, 1890: 489.

Sychnostigma Baltazar, 1961: 75.

Diagnosis (updated from Townes 1969 and Gauld 1991)

Small to large insects (fore wing length 6-25 mm), usually orange or yellow interspersed with black maculae; clypeus very small, not subdivided, often with a subapical ridge bearing median and/or lateral weak to strong tubercles; ventral margin of clypeus thin, slightly concave, often with lateral corners produced; mandible not twisted, stout, strongly constricted basally, then weakly tapered, apically bidentate with lower tooth pointed (may appear chisel-like when worn) and upper tooth blunt or chisellike; occipital carina complete to nearly absent, when ventrally present joining hypostomal carina above mandibular base; hypostomal carina strongly raised above mandible base; subocular sulcus absent, but malar area granulate; pronotum long, mid-dorsally with a deep invagination and with thin margin projecting beyond invagination; antero-lateral margin of pronotum broadly rounded in front, its lower corner acute and slightly in-turned; epomia weak to moderately strong, contiguous with and diverging from anterior pronotal margin; mesoscutum with strong transverse rugosities; notauli anteriorly strong and meeting in centre of mesoscutum, defining an anteriorly abruptly rounded median lobe; mesopleuron moderately long, epicnemial carina most often present laterally and reaching to or above lower corner of pronotum, its dorsal end evanescent; mesopleural suture weakly angled centrally; submetapleural carina weak to strong, more or less complete; propodeum of moderate length, without carina dorsally but pleural carina distinct; tarsal claws simple, large; fore wing with areolet open, $2 \mathrm{~m}-\mathrm{cu}$ slightly basal to distinctly apical to rs-m; hind wing with distal abscissa of $\mathrm{Cu}$ present, joining $\mathrm{Cu} \& \mathrm{cu}-\mathrm{a}$ near or at junction with $\mathrm{M}$; mid trochantellus with a ventral longitudinal ridge; metasoma moderately slender, tergites smooth to finely sculptured; tergite 1 fused with its sternite and without glymma; apical margins of tergites 3-5 hardly to strongly concave; female with sternites 2-4 (but see E. brianfisheri sp. nov.) with an anterior pair of tubercles, and with an apical truncate horn-like process on last tergite, ovipositor 
stout, laterally compressed, 4-5x longer than hind tibia; male with metasoma slenderer and subgenital plate elongate, posteriorly rather concave.

\section{Species richness and distribution (Yu et al. 2012)}

Epirhyssa is mostly circumtropical with some Far-Eastern species occurring up to Northern Japan; it includes 113 valid species with only six reported from the Afrotropical Region, to which we add here five new species.

Epirhyssa brianfisheri sp. nov. urn:1sid:zoobank.org:act:1C872313-52C3-4D81-B8AD-94AA2C724EAC

Fig. 1

\section{Diagnosis}

Overall color mottled, pale yellow and dark brown to black; wings hyaline, apically infuscate; face rugulose-punctate, strongly protruding medially; clypeus sparsely punctate, with median subapical tubercle strong and lateral subapical tubercle weak, ventral margin strongly produced laterally; frons rugulose with a blunt Y-shaped mid-longitudinal carina; antenna with 33 flagellomeres; mesopleuron with shallow transverse striations; epicnemial carina hardly reaching level of mesopleural pit; subtegular ridge convex; fore wing with $2 \mathrm{~m}$-cu opposite rs-m; tergite 1 slender; sternite 1 with an additional pair of basal tubercles; tergites 1-2 smooth, following tergites densely and finely punctate; apical margins of tergites 3-5 moderately concave. CT 3.3; ML 0.7; POL 2.0; OOL 1.5; $\mathrm{Fl}_{1} 4.2 ; \mathrm{Fl}_{15} 1.8 ; \mathrm{Fl}_{32} 1.2$; $\mathrm{T} 1$ 1.7; OT 3.9.

\section{Differential diagnosis}

Species characterized by the exceptional mottled coloration and the presence of antero-basal tubercles on sternite 1 ( $c f$. taxonomic remarks). All other species of Epirhyssa lack the antero-basal tubercles.

\section{Etymology}

Dedicated to Brian Fisher, friend and expert organizer of expeditions into central Africa, including the CAR expedition that discovered this species.

\section{Type material}

\section{Holotype}

CENTRAL AFRICAN REPUBLIC: + , Préfecture Sangha-Mbaéré, Réserve Spéciale de Forêt Dense de Dzanga-Sangha, $12.7 \mathrm{~km}, 326^{\circ} \mathrm{NW}$ of Bayanga, $3^{\circ} 00.27^{\prime} \mathrm{N} 16^{\circ} 11.55^{\prime} \mathrm{E}, 420 \mathrm{~m}, 13$ May 2001, S. van Noort, Sweep CAR01-S158, Lowland Rainforest, SAM-HYM-P048018 (SAMC).

\section{Description}

Female (holotype)

B 18.6; A11.0; F 12.8 .

Color. Head pale yellow with black to dark brown parts: mandible, malar space, median tubercle of clypeus, a thin mid-longitudinal line on upper face, frons, vertex, and most of occiput; mesosoma pale yellow with most of mesoscutum black, and testaceous to brown parts: anterior margin of pronotum, propleuron, most of mesopleuron but subtegular ridge and two lateral patches, mesosternum, ventral margin of metapleuron and anterior third of propodeum; metasoma dark brown with pale yellow markings: tergites 1-2 medially, tergite 3-4 posteriorly; sternites pale yellow, more or less extensively testaceous anteriorly; antenna dark brown with scape somewhat pale maculated; ovipositor sheath brown; fore and mid legs testaceous with coxae and tibiae mostly pale yellow, hind leg testaceous with 
coxa partly pale yellow and femur with an outer longitudinal pale yellow stripe; wings hyaline, fore wing anteriorly infuscate from pterostigma to apex.

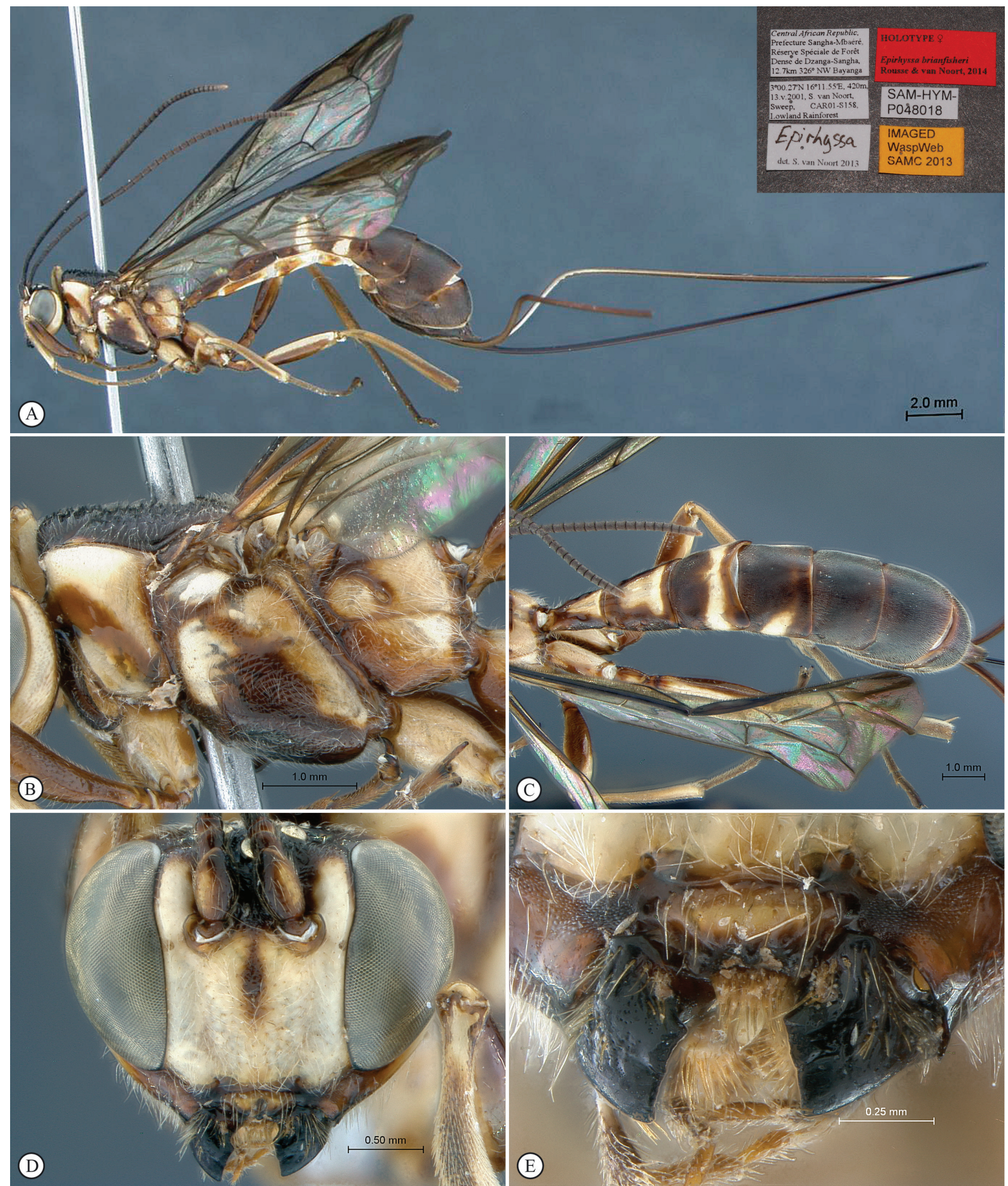

Fig. 1. Epirhyssa brianfisheri sp. nov., holotype, ․ A. Habitus, lateral view (inset: data labels). B. Mesosoma, lateral view. C. Metasoma, dorsal view. D. Head, anterior view. E. Mandibles, anterior view. 
HEAD. Densely setose with long hairs, hairs shorter on upper back head; face rugulose punctate, strongly protruding medially; clypeus sparsely punctate, subapical ridge with median tubercle strong and lateral tubercle weak, ventral margin strongly produced laterally; mandible stout; frons transversely rugose with a blunt Y-shaped mid-longitudinal carina below median ocellus, inner margins of toruli not expanded backwards; vertex and temple sparsely punctate but inter-ocellar area rugose; ocellar triangle wide; occipital carina mid-dorsally interrupted; antenna with 33 flagellomeres.

Mesosoma. Entirely covered with dense and long hairs; mesosoma moderately densely punctate, but mesonotum deeply transversely striate, anterior half of pronotum smooth and mesopleuron somewhat transversely strigose medially; epomia moderate; epicnemial carina hardly reaching level of mesopleural pit; apex of subtegular ridge convex, not flanged laterally; submetapleural carina strong, slightly and evenly narrowed toward apex.

WINGS. Fore wing with $2 \mathrm{~m}-\mathrm{cu}$ opposite rs-m, cu-a almost opposite Rs\&M, and Rs strongly bowed forwards; hind wing with distal abscissa of $\mathrm{Cu}$ joining $\mathrm{Cu} \& \mathrm{cu}-\mathrm{a}$ close to junction with $\mathrm{M}$, with a basal group of two hamuli on distal abscissa of R1.

Metasoma. Tergite 1 moderately slender; sternite 1 with a basal pair of submedian tubercles, additional to usual ones on sternites $2-4$; tergites $1-2$ mostly smooth, following tergites densely and finely punctate with fine transverse striations medially; apical margins of tergites 3-5 moderately concave.

Male

Unknown.

\section{Distribution}

Central African Republic.

\section{Taxonomic remarks}

The presence of tubercles on sternite 1 is quite unexpected in Epirhyssa, while it is one of the features defining the Oriental genus Triancyra Baltazar, 1961. However, we refrain from placing this new species in Triancyra for the following reasons. Besides the geographical separation from the known distribution area of Triancyra, the majority of morphological characters exhibited by this new species do not fit the current generic definition for Triancyra. For example, E. brianfisheri sp. nov. exhibits subequal mandibular teeth ( $v s$. upper tooth narrower in Triancyra), a pterostigma that is long and slender ( $v s$. up to $5 \mathrm{x}$ longer than high), hind wing with a basal group of two hamuli ( $v s$. usually three), tergite 1 long and slender ( $v s$. stout, 1.3x longer than wide) (Townes, 1969). Hence, we are of the opinion that the species fits more comfortably within Epirhyssa than in Triancyra, but the possession of additional tubercles in Epirhyssa species underlines the need for a global phylogenetic revision of the whole subfamily. Epirhyssa is indeed poorly defined and probably not monophyletic (G. Broad, pers. comm.).

Epirhyssa gavinbroadi sp. nov. urn:1sid:zoobank.org:act:94C30C69-E07C-4C48-BB79-3B3D903665EE

Fig. 2

\section{Diagnosis}

Bright yellow overall with isolated dorsal black markings; wings hyaline, slightly infuscate apically; face rugulose-punctate, moderately protruding dorsally; clypeus punctate, with median subapical tubercle moderate, ventral margin strongly produced laterally; frons smooth with a sharp mid-longitudinal carina reaching median ocellus and lateral curved carina toward lateral ocellus; antenna with more than 35 flagellomeres; mesopleuron with epicnemial carina reaching level of mesopleural pit; subtegular ridge 


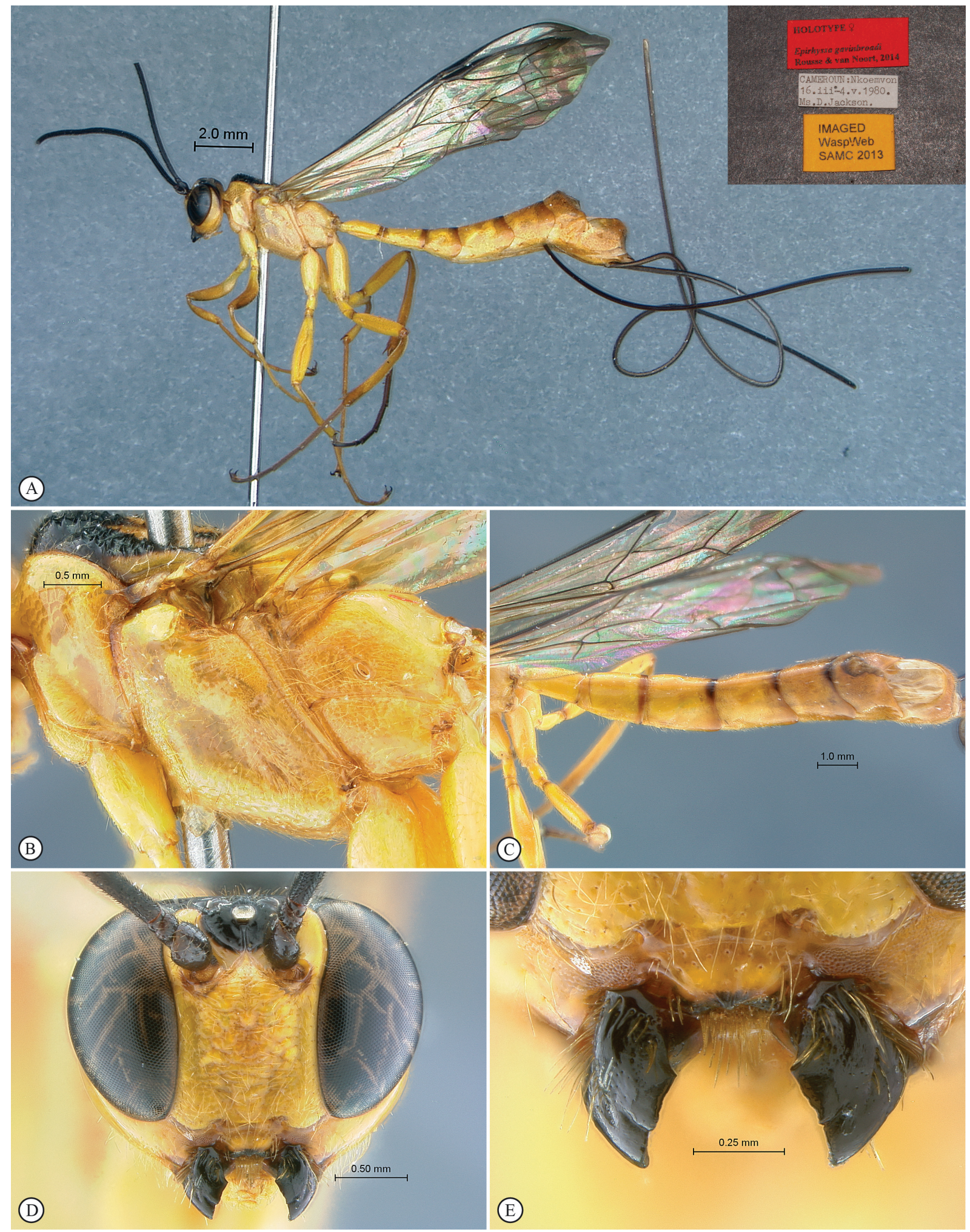

Fig. 2. Epirhyssa gavinbroadi sp. nov., holotype, +. A. Habitus, lateral view (inset: data labels). B. Mesosoma, lateral view. C. Metasoma, dorsal view. D. Head, anterior aview. E. Mandibles, anterior view. 
concave, laterally flanged; fore wing with $2 \mathrm{~m}-\mathrm{cu}$ slightly apical to $\mathrm{rs}-\mathrm{m}$; tergite 1 slender; tergites $1-5$ smooth, following tergites densely and finely punctate; apical margins of tergites $3-7$ strongly concave. CT 2.7; ML 0.5; POL 1.3; OOL1.6; $\mathrm{Fl}_{1} 4.2 ; \mathrm{Fl}_{15}$ 1.8; T1 1.7; OT 5.2.

\section{Differential diagnosis}

A mostly bright yellow species with hyaline wings, otherwise characterized by the combination of the punctate clypeus, the concave and flanged subtegular ridge, and the sharp mid-longitudinal carina on the frons, which separates this species from other yellow species with hyaline wings (these species have a strigose or hardly sculptured clypeus, and all of them except E. uelensis have no flange on the subtegular ridge).

\section{Etymology}

Dedicated to Gavin Broad for his constant support and his most valuable advice.

\section{Type material}

\section{Holotype}

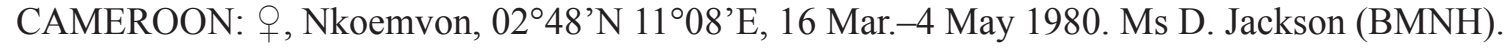

\section{Description}

Female (holotype)

B 15.7; A NA; F 12.1 .

COLOR. Bright yellow overall with black markings: mandible, mid-apical tubercle on clypeus, vertex, temple, occiput mid-dorsally, mesoscutum but postero-lateral margins and a central macula, and a small mid-posterior macula on tergites 3-6; flagellum and ovipositor sheath dark brown; wings hyaline, slightly infuscate apically, venation brown.

HEAD. Face rugulose punctate, moderately protruding dorsally; clypeus punctate, with a moderate subapical median tubercle, ventral margin strongly produced laterally; mandible stout; frons smooth; inner margins of toruli expanded backwards into two converging lamellar carinae, carinae then fused into a sharp mid-longitudinal carina reaching median ocellus; frons also with an additional lateral curved carina from posterior margin of torulus to next to lateral ocellus; inter-ocellar area rugose, remainder of vertex and temple finely punctate; occipital carina mid-dorsally evanescent; antenna with more than 35 flagellomeres (apices broken).

Mesosoma. Mesosoma moderately densely punctate, but mesonotum deeply transversely striate and anterior half of pronotum smooth; epomia very weak; epicnemial carina reaching level of mesopleural pit; apex of subtegular ridge concave, strongly flanged laterally; submetapleural carina slightly and evenly narrowed toward apex.

WINGS. Fore wing with $2 \mathrm{~m}-\mathrm{cu}$ slightly apical to $\mathrm{rs}-\mathrm{m}$, cu-a slightly apical to Rs\&M, and Rs strongly bowed forwards; hind wing with distal abscissa of $\mathrm{Cu}$ joining $\mathrm{Cu} \& \mathrm{cu}-\mathrm{a}$ close to junction with $\mathrm{M}$.

Metasoma. Tergite 1 moderately slender; tergites 1-5 mostly smooth, apex of tergite 5 and following tergites finely and densely punctate; apical margins of tergites 3-7 strongly concave.

\section{Male}

Unknown. 


\section{Distribution}

Cameroon.

Epirhyssa ghesquierei Seyrig, 1937

Fig. 3

\section{Diagnosis}

Bright yellow overall with isolated dorsal black markings; wings hyaline, slightly infuscate apically; face deeply rugulose-punctate, moderately protruding dorsally; clypeus nearly smooth, with median subapical tubercle strong, ventral margin produced laterally; frons laterally punctate and medially rugulose, with two weak submedian carinae diverging below median ocellus toward lateral ocelli; antenna with 34 flagellomeres; mesopleuron with epicnemial carina reaching above level of mesopleural pit; subtegular ridge convex; fore wing with $2 \mathrm{~m}$-cu slightly apical to rs-m; tergite 1 slender; tergites 1-2 smooth, following tergites shallowly punctate with basal transverse striations; apical margins of tergites straight. CT 2.7; ML 0.7; POL 1.1; OOL 1.3; $\mathrm{Fl}_{1} 4.1 ; \mathrm{Fl}_{15} 2.2 ; \mathrm{Fl}_{33} 1.1$; T1 2.5; OT 4.2.

\section{Differential diagnosis}

A mostly bright yellow species with hyaline wings, otherwise characterized by the combination of the pair of submedian carinae on the frons diverging towards the lateral ocelli and the slender tergite 1 . The other yellow species with hyaline wings have a stouter tergite 1 in the female, less than twice as long as apically wide.

\section{Material examined}

Holotype

DEMOCRATIC REPUBLIC OF CONGO: + , Eala [0040’N 18¹7’E], Nov. 1935, J. Ghesquière, R. Dét. G 3330 (MRAC).

\section{Paratype}

DEMOCRATIC REPUBLIC OF CONGO: 1 ð̊, Bambesa, Dec. 1946, P.L. Benoit (MRAC).

\section{Other material}

CAMEROON: 1 ðૈ, Korup, Dec. 1980-Jan. 1981, Mrs D. Jackson (BMNH); 1 ð, Korup, 1981, Mrs D. Jackson (BMNH).

\section{Description}

Female (holotype)

B 14.6; A 12.2; F 12.1 .

COLOR. Bright yellow overall, with black markings on mandible, vertex, upper occiput, and mesoscutum margins; antenna and ovipositor sheath dark brown; wings hyaline, apex hardly infuscate, venation pale brown.

HEAD. Face subquadrate, deeply rugulose punctate and moderately protruding dorsally; clypeus almost smooth, with a strong subapical median tubercle, ventral margin produced laterally; mandible stout; frons laterally moderately punctate, medially smoothly rugulose; inner margins of toruli expanded backwards into two weak sinuate submedian carinae, carinae then diverging and reaching lateral ocelli; vertex and temple slightly and finely punctate; occipital carina complete but mid-dorsally faint; antenna with 34 flagellomeres. 
Mesosoma. Mesosoma shallowly and moderately densely punctate, but mesonotum deeply transversely striate and anterior half of pronotum smooth; epomia very weak; epicnemial carina long, its evanescent dorsal end reaching above level of mesopleural pit; apex of subtegular ridge convex, not flanged laterally; submetapleural carina thick, evenly narrowed toward apex.
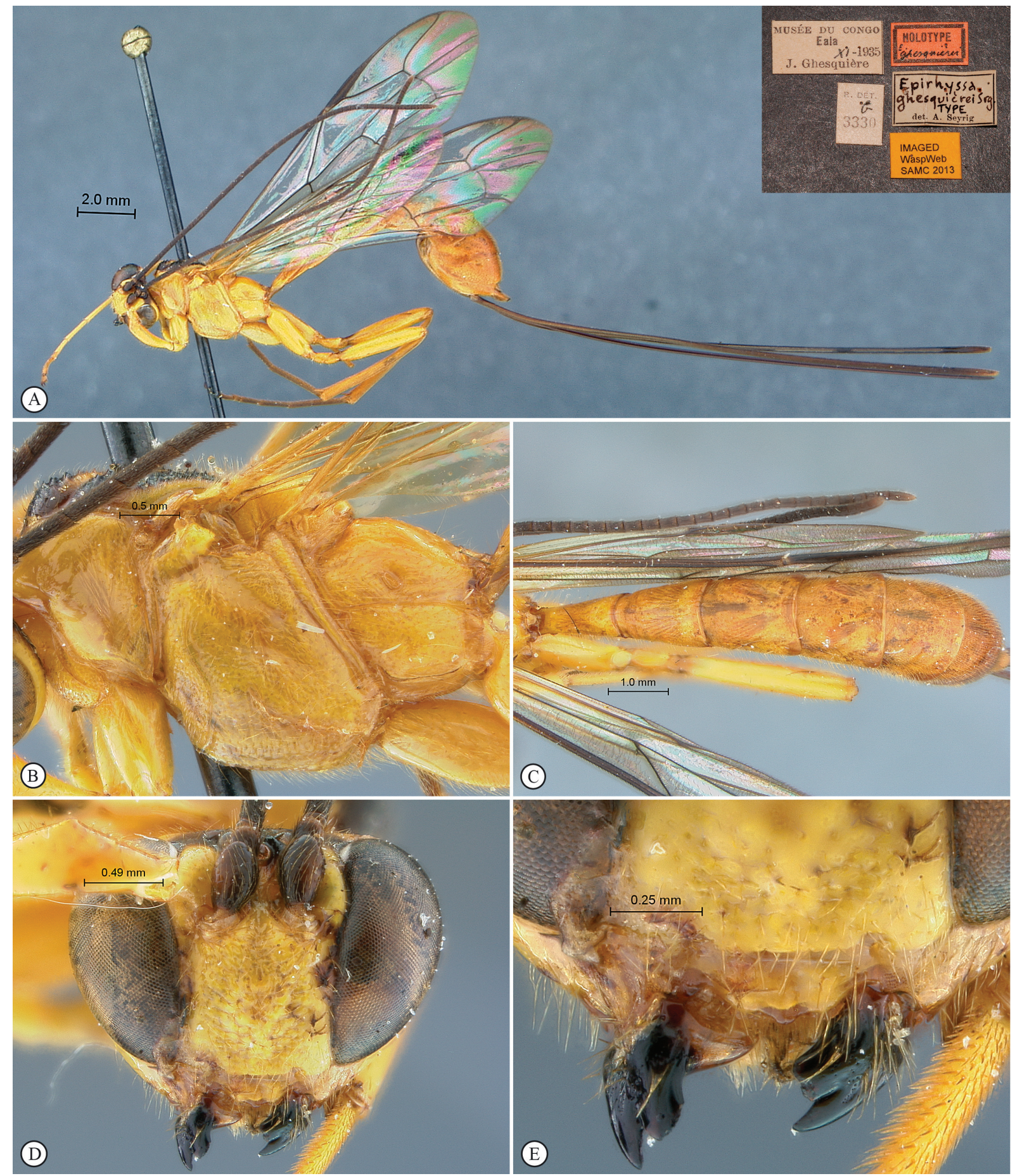

Fig. 3. Epirhyssa ghesquierei Seyrig, 1937, holotype,, . A. Habitus, lateral view (inset: data labels). B. Mesosoma, lateral view. C. Metasoma, dorsal view. D. Head, anterior view. E. Mandibles, anterior view. 
WINGs. Fore wing with $2 \mathrm{~m}-\mathrm{cu}$ slightly apical to rs-m, cu-a slightly apical to Rs\&M, and Rs weakly bowed forwards; hind wing with distal abscissa of $\mathrm{Cu}$ joining $\mathrm{Cu} \& \mathrm{cu}-\mathrm{a}$ close to junction with $\mathrm{M}$.

Metasoma. Tergite 1 slender and smooth, tergite 2 mostly smooth with some superficial punctures laterally, tergites 3-6 shallowly punctate with basal transverse striations; apical margins of all tergites straight.

Male (3 specimens)

B 11.8-13.6; A 15.1-16.2; F 14.9-16.0.

Similar to female but tergite 1 slenderer (T1 2.5); the two males from Cameroon are significantly lighter, without dorsal black markings.

\section{Distribution}

Democratic Republic of Congo. New record: Cameroon.

Epirhyssa leroyi Benoit, 1951

Fig. 4

\section{Diagnosis}

Bright yellow overall with black markings including entire mesosternum, metasoma fading to brown apically; wings hyaline, slightly infuscate apically; face rugulose-punctate, strongly protruding medially; clypeus nearly smooth, with median and lateral subapical tubercles moderate, ventral margin produced laterally; frons laterally punctate and medially striate, with a blunt Y-shaped mid-longitudinal carina; mesopleuron with epicnemial carina reaching above level of mesopleural pit; subtegular ridge convex; fore wing with $2 \mathrm{~m}-\mathrm{cu}$ slightly basal to $\mathrm{rs}-\mathrm{m}$; tergite 1 of female stout (male unknown); tergites 1-3 smooth, following tergites shallowly punctate with basal transverse striations; apical margins of tergites 3-4 slightly concave. CT 3.6; ML 0.6; POL 1.6; OOL 1.4; Fl 3 3.4; Fl ${ }_{15} \mathrm{NA}$; T1 1.2-1.4; OT 4.4.

\section{Differential diagnosis}

A mostly bright yellow species with hyaline wings, otherwise characterized by the combination of the black mesosternum, vein $2 \mathrm{~m}-\mathrm{cu}$ slightly basal to rs-m and the stout tergite 1 (at least in the female). All other yellow Afrotropical Epirhyssa species have the mesosternum concolorous with the remainder of the mesosoma and the vein $2 \mathrm{~m}-\mathrm{cu}$ slightly apical to rs-m.

\section{Material examined}

Holotype

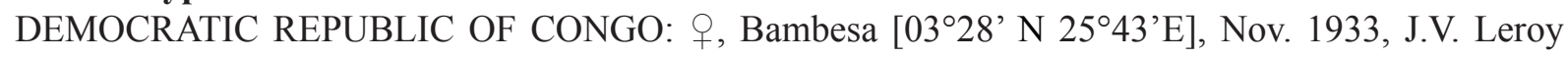
(MRAC).

\section{Paratype}

DEMOCRATIC REPUBLIC OF CONGO: + , Ubangui-Bumba, Dec. 1939, H. de Saeger (MRAC).

\section{Description}

Female (holotype)

B 14.9; A NA; F 11.1.

Color. Bright to dull yellow overall, with metasoma fading to brown toward apex, and with black markings: mandible, ventral margin of clypeus, ocellar area (macula connected to eye margin), occiput 

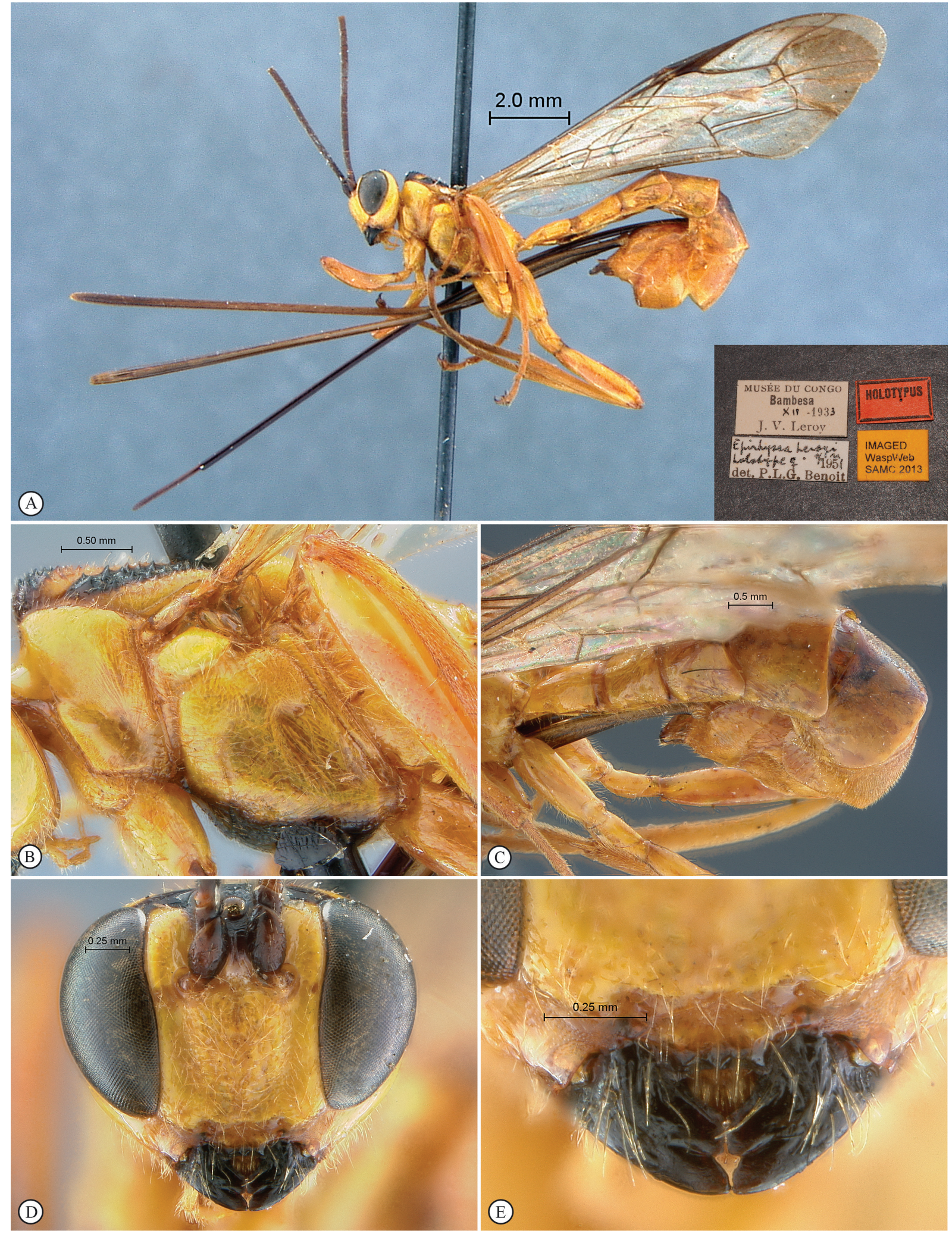

Fig. 4. Epirhyssa leroyi Benoit, 1951, holotype, + . A. Habitus, lateral view (inset: data labels). B. Mesosoma, lateral view. C. Metasoma, dorsal view. D. Head, anterior view. E. Mandibles, anterior view. 
mid-dorsally, mesosternum, and a median macula on each mesoscutal lobe; antenna and ovipositor sheath dark brown; wings hyaline, slightly infuscate apically, venation pale brown.

HEAD. Face rugulose-punctate, strongly bulging medially; clypeus smoothly sculptured with distinct lateral and median subapical tubercles, ventral margin strongly produced laterally; mandible short and stout; frons laterally sparsely punctate, medially transversely striate with a blunt Y-shaped midlongitudinal carina below median ocellus, inner margins of toruli not expanded backwards; temple and vertex finely punctate, inter-ocellar area somewhat rugose; occipital carina mid-dorsally interrupted; antenna broken in both specimens.

Mesosoma. Mesosoma shallowly and moderately densely punctate, but mesonotum deeply transversely striate and anterior half of pronotum smooth; epomia moderate; epicnemial carina long, its evanescent dorsal end reaching above level of mesopleural pit; apex of subtegular ridge convex, not flanged laterally; submetapleural carina anteriorly expanded, then distinctly narrowed toward apex.

Wings. Fore wing with $2 \mathrm{~m}-\mathrm{cu}$ slightly basal to rs-m, cu-a slightly apical to Rs\&M, and Rs weakly bowed forwards; hind wing with distal abscissa of $\mathrm{Cu}$ joining $\mathrm{Cu} \& \mathrm{cu}-\mathrm{a}$ close to junction with $\mathrm{M}$.

Metasoma. Tergite 1 stout and smooth, tergites $2-3$ nearly smooth, following tergites finely and distinctly punctate with weak basal striations; apical margins of tergites 3-4 slightly concave, others straight.

\author{
Male \\ Unknown.

\section{Distribution} \\ Democratic Republic of Congo.
}

Epirhyssa maynei Benoit, 1952

Fig. 5

\title{
Diagnosis
}

Bright yellowish-orange overall with dark dorsal markings including apical half of metasoma; wings yellowish with apices strongly infuscate and an additional infuscate transverse subapical stripe on fore wing; face sparsely punctate, barely protruding; clypeus nearly smooth, without subapical tubercle, ventral margin truncate; frons smooth with a blunt Y-shaped mid-longitudinal carina; antenna with 37 flagellomeres; epicnemial carina hardly extending onto mesopleuron; subtegular ridge convex; fore wing with $2 \mathrm{~m}-\mathrm{cu}$ opposite rs-m; tergite 1 stout; all tergites smooth, with fine isolated punctures; apical margins of tergites $3-5$ strongly concave. CT 2.9; ML 0.5; POL 1.3; OOL 1.3; $\mathrm{Fl}_{1} 3.7 ; \mathrm{Fl}_{15} 2.5 ; \mathrm{Fl}_{36} 1.2$; T1 1.2.

\section{Differential diagnosis}

Species characterized by its coloration, with apical half of metasoma black, wings yellowish with black patterns; otherwise characterized by the combination of the sparsely punctate face, the absence of subapical protuberances on the clypeus, the ventral margin of the clypeus not produced laterally, and the epicnemial carina nearly absent laterally. It is the only yellow Afrotropical species with banded wings.

\section{Material examined}

\section{Holotype}

DEMOCRATIC REPUBLIC OF CONGO: 今̊, Albertville [Kalemie, 0556’N 29¹2’E], Jul. 1918, R. Mayné (MRAC). 


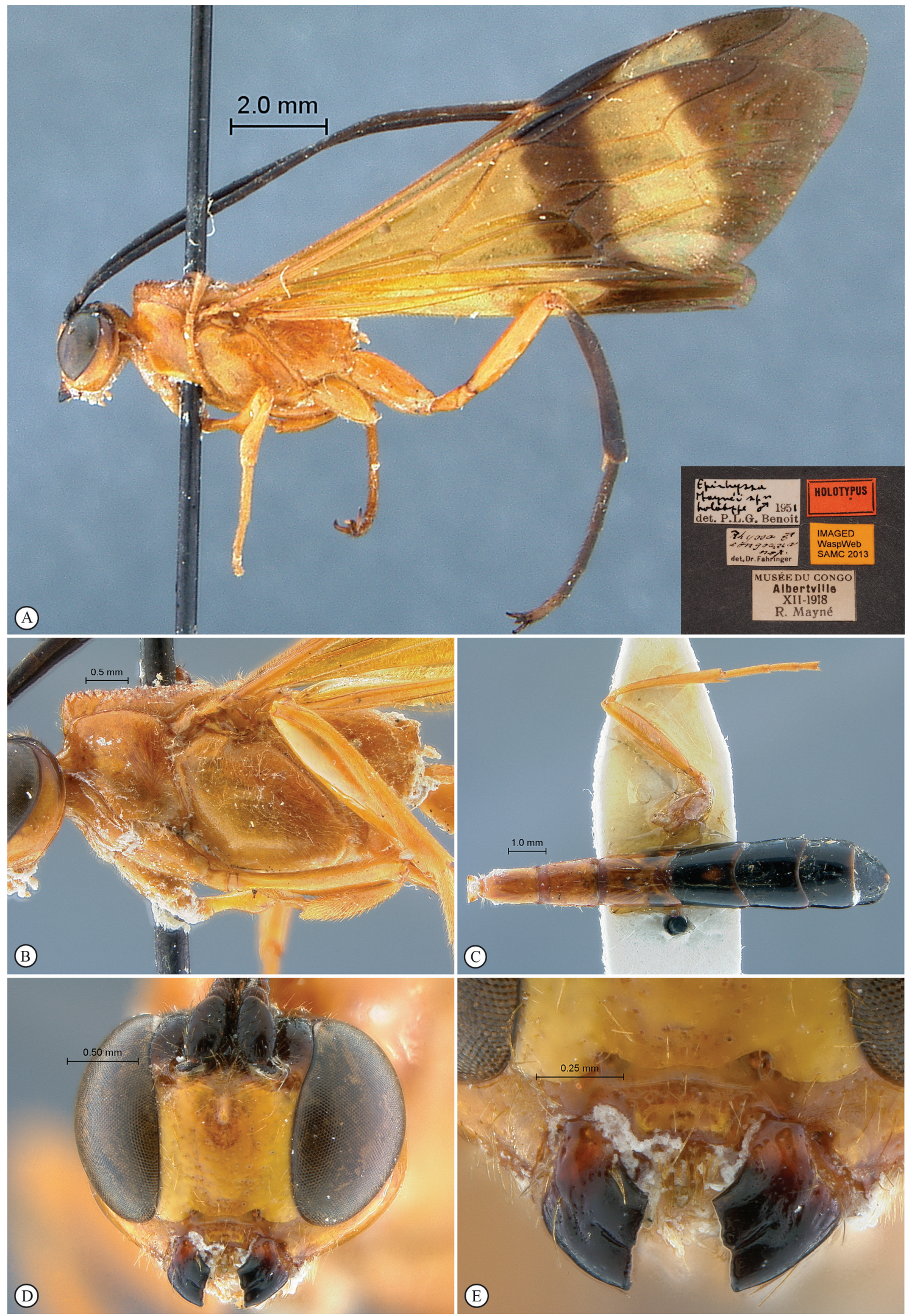

Fig. 5. Epirhyssa maynei Benoit, 1952, holotype, q. A. Habitus, lateral view (inset: data labels). B. Mesosoma, lateral view. C. Metasoma, dorsal view. D. Head, anterior view. E. Mandibles, anterior view. 


\section{Paratype}

DEMOCRATIC REPUBLIC OF CONGO: 1 ð̊, Bambesa, Dec. 1946, P.L. Benoit (MRAC).

\section{Other material}

CENTRAL AFRICAN REPUBLIC: 1 ô, Préfecture Sangha-Mbaéré, Parc National de Dzanga-Ndoki, $38.6 \mathrm{~km}, 173^{\circ} \mathrm{S}$ of Lidjombo, $2^{\circ} 21.60^{\prime} \mathrm{N} 16^{\circ} 09.20^{\prime} \mathrm{E}, 350 \mathrm{~m}, 27$ May 2001, S. van Noort, handnet, Lowland Rainforest, CAR01-H25, SAM-HYM-P049437 (SAMC).

\section{Description}

Female

Unknown.

Male (3 specimens)

B 14.2-16.7; A 13.6-14.9; F 11.5-13.3 (holotype: B 16.7; A 14.9; F 13.3).

Color. Bright yellowish orange overall with dark brown to black markings: apical $2 / 3$ of mandible, frons, vertex, temple, hind leg from femur and metasoma from tergite 4; flagellum dark brown; wings yellowish, apically strongly infuscate, fore wing with an additional transverse infuscate stripe at pterostigma level, venation yellow.

HEAD. Face sub-quadrate, sparsely punctate, barely protruding dorsally but with a short mid-longitudinal ridge near toruli; clypeus mostly smooth with some punctures along dorsal margin, without distinct subapical tubercle, ventral margin truncate; mandible stout, both teeth truncate and chisel-like; upper head quite smooth; frons with a blunt Y-shaped mid-longitudinal carina below median ocellus, inner margins of toruli not expanded backwards; occipital carina mid-dorsally evanescent; antenna with 3437 flagellomeres.

Mesosoma. Mesosoma shallowly and moderately densely punctate, but mesonotum deeply transversely striate and anterior half of pronotum smooth; epomia very weak; epicnemial carina very short, hardly extending laterally onto mesopleuron; apex of subtegular ridge convex, not flanged laterally; submetapleural carina anteriorly moderately expanded, then abruptly narrowed from anterior third.

WINGs. Fore wing with $2 \mathrm{~m}-\mathrm{cu}$ opposite rs-m, cu-a distinctly apical to Rs\&M, Rs moderately bowed forwards; hind wing with distal abscissa of $\mathrm{Cu}$ joining $\mathrm{Cu} \& \mathrm{cu}-\mathrm{a}$ at its anterior third, remote from junction with $\mathrm{M}$.

Metasoma. Tergite 1 slender; all tergites smooth but with fine isolated punctures; apical margins of tergites $3-5$ strongly concave.

\section{Distribution}

Democratic Republic of Congo. New record: Central African Republic.

Epirhyssa migratoria Seyrig, 1932

\section{Diagnosis}

Fig. 6

Bright yellow overall with isolated dorsal black markings; wings hyaline, slightly infuscate apically; face sparsely punctate, almost flat; clypeus nearly smooth, with median and lateral subapical tubercles moderate, ventral margin produced laterally; frons smooth, with two submedian carinae diverging below median ocellus toward lateral ocelli; antenna with 36 flagellomeres; epicnemial carina laterally absent; subtegular ridge convex; fore wing with $2 \mathrm{~m}$-cu slightly apical to $\mathrm{rs}-\mathrm{m}$; tergite 1 weakly slender in 
female, much more slender in male; tergites 1-3 smooth, following tergites sparsely punctate with basal transverse striations; apical margins of tergites 3-5 moderately concave. CT 2.5; ML 0.6; POL 2.6; OOL 1.3; $\mathrm{Fl}_{1} 4.4 ; \mathrm{Fl}_{15} 2.3 ; \mathrm{Fl}_{35} 1.1 ; \mathrm{T} 1$ 1.4-1.5; OT 5.0.
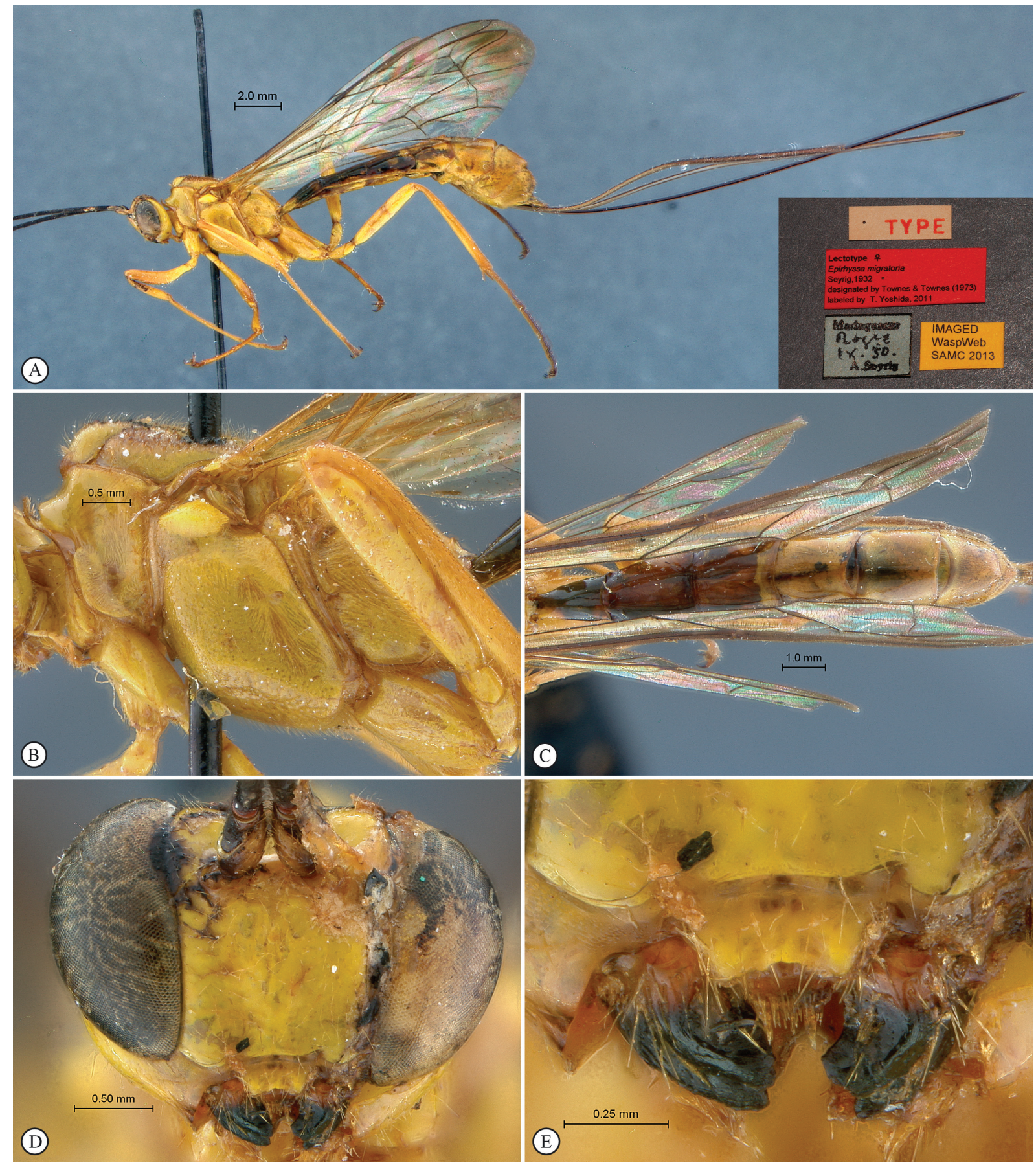

Fig. 6. Epirhyssa migratoria Seyrig, 1932, holotype,, . A. Habitus, lateral view (inset: data labels). B. Mesosoma, lateral view. C. Metasoma, dorsal view. D. Head, anterior view. E. Mandibles, anterior view. 


\section{Differential diagnosis}

A mostly bright yellow species with hyaline wings, otherwise characterized by the combination of the flat and sparsely punctate face, the pair of submedian carinae on the frons and the absence of the epicnemial carina on the mesopleuron. The lateral part of the epicnemial carina is distinct in every other yellow species with hyaline wings.

\section{Material examined}

\section{Lectotype}

MADAGASCAR: + , Rogez [ $48^{\circ} 18^{\prime}$ 'S 48³2’E], Sep. 30, A. Seyrig, MNHN EY8815.

\section{Paratypes}

$3 \widehat{\jmath} \widehat{\jmath}$, same label data.

\section{Description}

Female (holotype)

B 18.2; A 15.1; L 14.7.

COLOR. Bright yellow overall with infuscate to black markings: mandible, inter-ocellar area (macula connected to eye margin), dorsal margin of occiput, mesoscutal lobes mid-longitudinally, and scutoscutellar groove; antenna and ovipositor sheath mostly dark brown; wings nearly hyaline, apically slightly infuscate, venation testaceous.

HEAD. Face sparsely punctate, almost flat; clypeus smoothly sculptured with moderate lateral and median subapical tubercles, ventral margin moderately produced laterally; mandible stout; upper head quite smooth to moderately and shallowly punctate, inter-ocellar area somewhat rugose; frons with a pair of submedian carinae, carinae abruptly diverging below median ocellus and following anterior margin of vertex, inner margins of toruli hardly produced backwards; occipital carina mid-dorsally interrupted; antenna with 36 flagellomeres.

Mesosoma. Mesosoma shallowly and moderately densely punctate, but mesonotum transversely striate and anterior half of pronotum smooth; epomia weak; epicnemial carina absent except for a short ventral remnant; apex of subtegular ridge convex, not flanged laterally; submetapleural carina strong and even all along.

WINGs. Fore wing with $2 \mathrm{~m}-\mathrm{cu}$ slightly apical to rs-m, cu-a slightly apical to Rs\&M, and Rs moderately bowed forwards; hind wing with distal abscissa of $\mathrm{Cu}$ joining $\mathrm{Cu} \& \mathrm{cu}-\mathrm{a}$ close to junction with $\mathrm{M}$.

Metasoma. Tergite 1 moderately slender; tergites 1-3 smooth, following tergites finely and sparsely punctate with basal transverse striations; apical margins of tergites 3-5 moderately concave, others straight.

Male (3 specimens)

B 17.5-18.2; A14.3-14.9; L 14.0-14.5.

Similar to female but metasoma much more slender (T1 2.0-2.2).

\section{Distribution}

\section{Madagascar.}


Epirhyssa overlaeti Seyrig, 1937

Fig. 7

\section{Diagnosis}

Overall color mottled, black, yellow and testaceous; wings hyaline, slightly infuscate apically; face transversely striate, nearly flat; clypeus shallowly and sparsely punctate, without subapical tubercle, ventral margin strongly produced laterally; frons smooth, with a sharp mid-longitudinal carina reaching median ocellus and lateral curved carina toward lateral ocellus; antenna with 41-43 flagellomeres; epicnemial carina reaching lower level of speculum; fore wing with $2 \mathrm{~m}-\mathrm{cu}$ opposite rs- $\mathrm{m}$; tergite 1 slender; all tergites nearly to quite smooth, tergites $4-5$ finely transversely striate basally; apical margins of tergites 3-6 strongly concave. CT 2.5; ML 0.5; POL 1.3; OOL 1.6; $\mathrm{Fl}_{1} 3.9 ; \mathrm{Fl}_{15} 2.8 ; \mathrm{Fl}_{42} 1.3 ; \mathrm{T1} 1.7$; OT 7.2.

\section{Differential diagnosis}

Highly distinctive species of mottled color and large to very large size; otherwise characterized by the combination of the flat and sparsely punctate face, the sharp mid-longitudinal carina on the frons, the absence of a subapical ridge on the clypeus, and the very long ovipositor. No other known Epirhyssa species shares this color pattern.

\section{Material examined}

\section{Holotype}

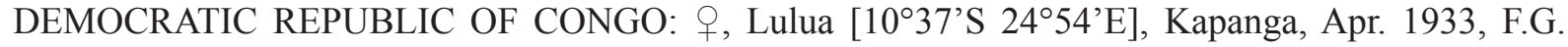
Overlaet, R. Dét. F 3330 (MRAC).

\section{Other material}

CAMEROON: 1 , Nkoemvon, Jul.-Aug. 1980, Ms. D. Jackson (BMNH).

\section{Description}

Female (2 specimens)

$$
\text { B 25.2-37.8; A 15.4-23.2; F 16.1-24.2. }
$$

CoLor. Head yellow with mandible black and lower gena, vertex and upper occiput brownish testaceous; mesosoma black to dark brownish testaceous interspersed with yellow markings: pronotum dorsally and ventrally, mesopleuron anteriorly and posteriorly, and mesoscutum, scutellum, metanotum and propodeum centrally; legs testaceous to dark testaceous with fore and mid coxa yellow; metasoma light to dark testaceous, tergites 1-5 with apico-lateral large yellow spots; antenna and ovipositor sheath dark brown; wings nearly hyaline, apically infuscate, venation dark brown.

HEAD. Face subquadrate, transversely striate and hardly bulging medially; clypeus shallowly and sparsely punctate, without subapical tubercle, ventral margin strongly produced laterally; mandible stout; upper head quite smooth; inner margins of toruli expanded backwards into two converging lamellar carinae, carinae then fused into a sharp mid-longitudinal carina reaching median ocellus; frons also with an additional lateral curved carina from posterior margin of torulus to next to lateral ocellus; occipital carina mid-dorsally interrupted; antenna with 41-43 flagellomeres.

Mesosoma. Mesosoma shallowly and moderately densely punctate, but mesonotum transversely striate and anterior half of pronotum smooth; epomia indistinct; epicnemial carina reaching lower level of speculum, mesopleural pit indistinct; apex of subtegular ridge convex, not flanged laterally; submetapleural carina moderate and even all along. 
WINGS. Fore wing with $2 \mathrm{~m}$-cu opposite rs-m, cu-a slightly apical to Rs\&M, and Rs short and moderately bowed forwards; hind wing with distal abscissa of $\mathrm{Cu}$ joining $\mathrm{Cu} \& \mathrm{cu}-\mathrm{a}$ at junction with $\mathrm{M}$.

Meталома. Tergite 1 moderately slender; all tergites smooth to indistinctly sculptured but tergites 4-5 weakly striate basally; apical margins of tergites 3-6 strongly concave, others straight.

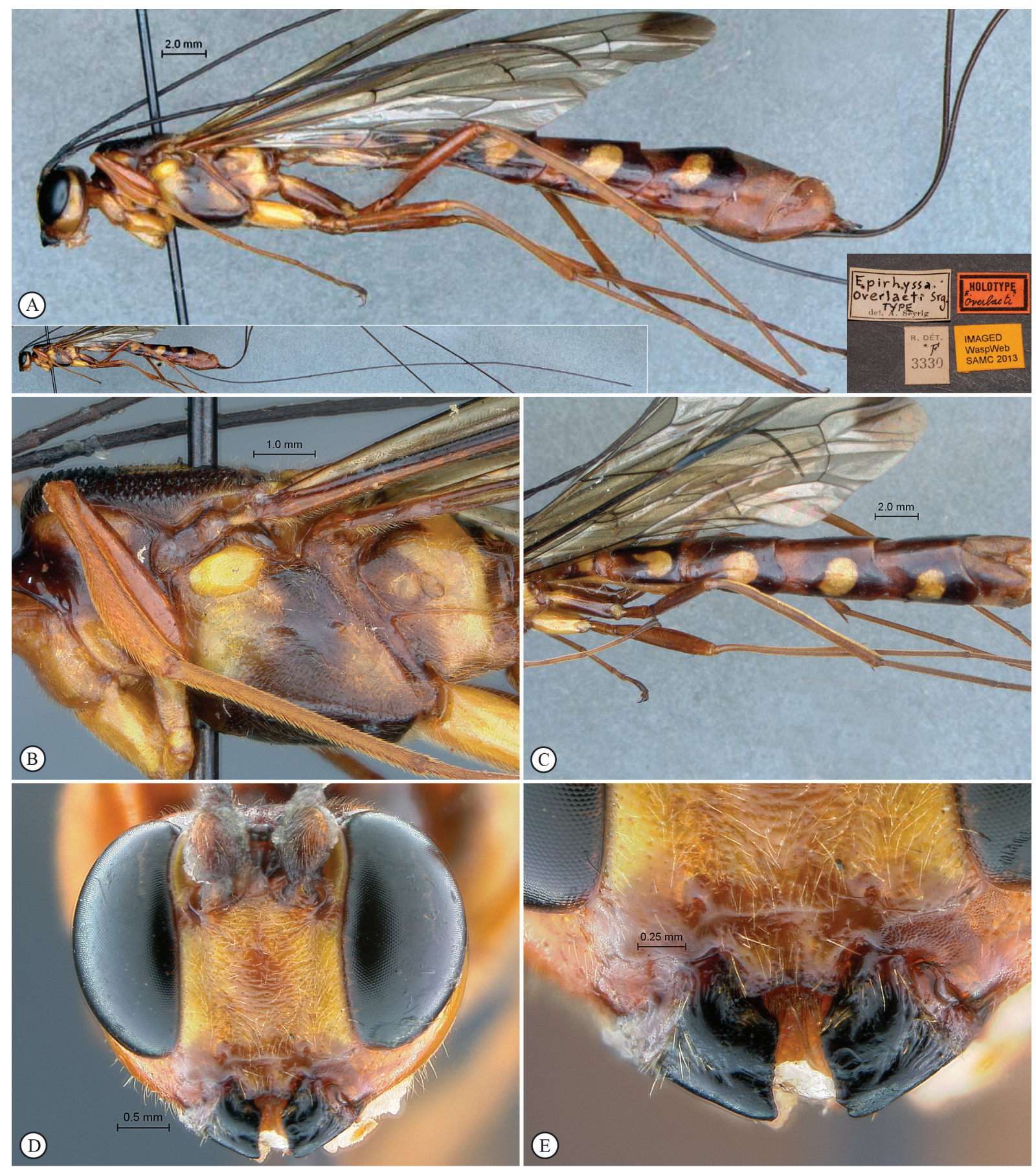

Fig. 7. Epirhyssa overlaeti Seyrig, 1937, holotype, + . A. Habitus, lateral view (inset: data labels). B. Mesosoma, lateral view. C. Metasoma, dorsal view. D. Head, anterior view. E. Mandibles, anterior view. 
Male

Unknown.

\section{Distribution}

Democratic Republic of Congo. New record: Cameroon.

\section{Comments}

The species is only known from two female specimens. They exhibit a remarkable variation in size, the BMNH specimen being one third smaller than the impressively large MRAC holotype.

Epirhyssa shaka sp. nov. urn:1sid:zoobank.org:act:CF997FDF-A6A7-49A1-9DCA-C5F781CACEE1

Fig. 8

\section{Diagnosis}

Pale yellow overall with isolated dorsal black markings; wings hyaline, slightly infuscate apically; face rugulose-punctate, weakly bulging; clypeus shallowly longitudinally strigose with a strong subapical median tubercle, ventral margin produced laterally; frons smooth, with a weak mid-longitudinal carina; antenna with 32 flagellomeres; mesopleuron with epicnemial carina reaching level of mesopleural pit; subtegular ridge convex; fore wing with $2 \mathrm{~m}-\mathrm{cu}$ slightly apical to $\mathrm{rs}-\mathrm{m}$; tergite 1 slender; tergite 1 smooth, following tergites densely punctate; apical margins of all tergites straight. CT 3.8; ML 0.7; POL 1.3; OOL 1.2; $\mathrm{Fl}_{1} 4.5 ; \mathrm{Fl}_{15} 1.8 ; \mathrm{Fl}_{31} 1.0 ; \mathrm{T} 1$ 1.7; OT 3.9.

\section{Differential diagnosis}

Pale yellow species of relatively small size, otherwise characterized by the combination of the weak mid-longitudinal carina on the frons, the entirely punctate tergite 2 and the slender tergite 1.

\section{Etymology}

Refers to King Shaka Zulu, another kind of population regulator of the Zululand region. He would certainly have been proud of giving his name to an ichneumon.

\section{Type material}

\section{Holotype}

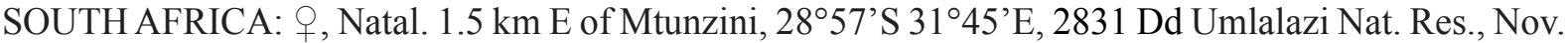
1978, R. M. Miller, indigenous forest, Malaise tr. (NMSA).

\section{Description}

Female (holotype)

B 11.9; A 9.6; F 8.7.

CoLOR. Pale dull yellow overall with black parts: mandible, ocellar area (macula isolated from eye margin), a median spot on each mesoscutal lobe, scuto-scutellar groove, a mid-longitudinal triangle at base of tergites 4-6; flagellum dark brown; hind tarsus and ovipositor sheath reddish-brown; wings hyaline, barely infuscate apically, venation yellowish.

HEAD. Face subquadrate, weakly bulging mid-dorsally, rugulose punctate and laterally smoother; clypeus shallowly longitudinally strigose, with a strong and acute subapical median tubercle, ventral margin laterally produced; mandible stout; frons smooth; inner margins of toruli expanded backwards into two 

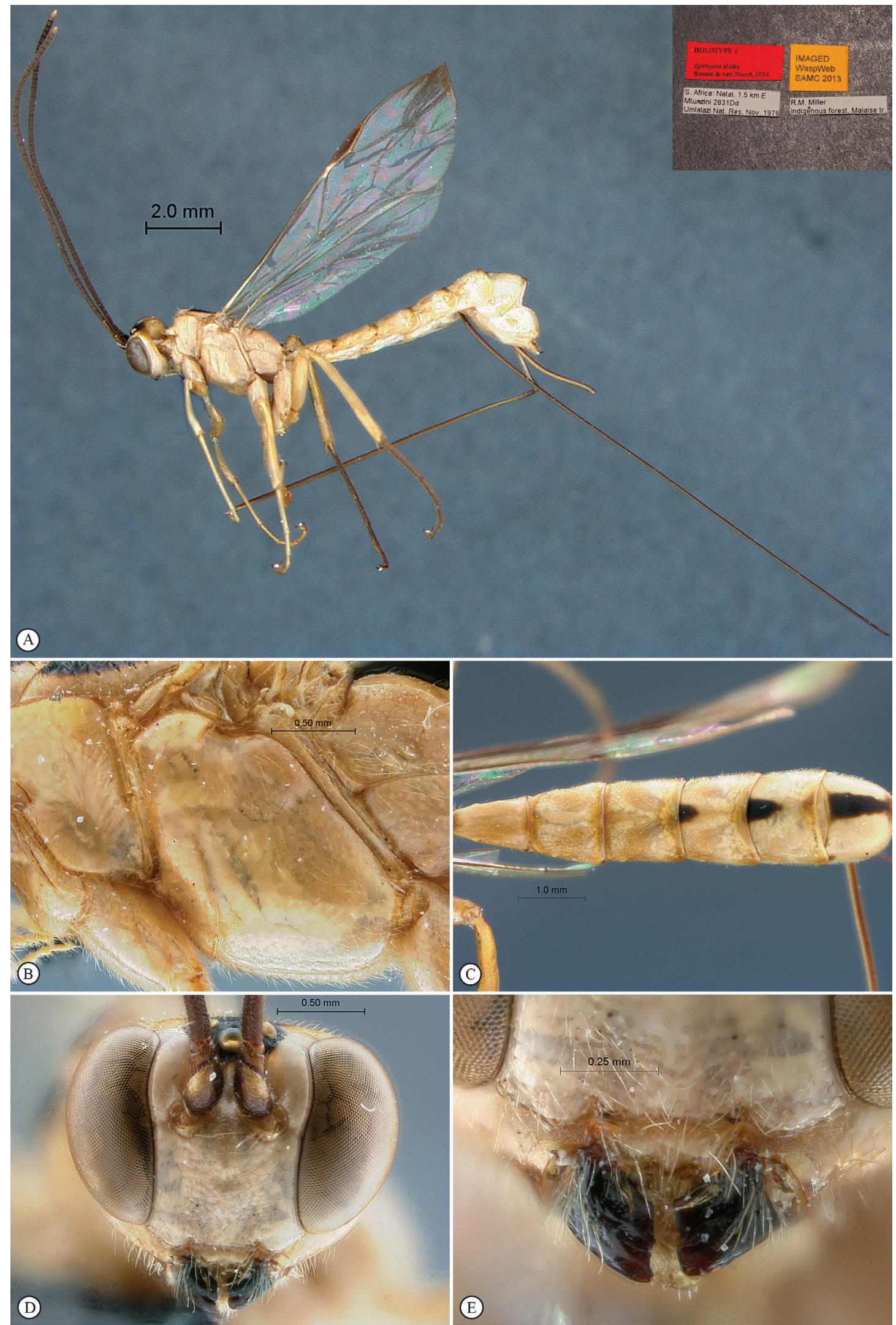

Fig. 8. Epirhyssa shaka sp. nov., holotype,, . A. Habitus, lateral view (inset: data labels). B. Mesosoma, lateral view. C. Metasoma, dorsal view. D. Head, anterior view. E. Mandibles, anterior view. 
converging carinae, carinae then fused into a weak mid-longitudinal carina reaching median ocellus; vertex and temple moderately punctate; occipital carina complete; antenna with 32 flagellomeres.

Mesosoma. Mesosoma shallowly and moderately densely punctate, but mesonotum deeply transversely striate and anterior half of pronotum smooth; epomia moderate; dorsal faint apex of epicnemial carina reaching level of mesopleural pit; apex of subtegular ridge convex, not flanged laterally; submetapleural carina slightly and evenly narrowed toward apex.

Wings. Fore wing with $2 \mathrm{~m}-\mathrm{cu}$ slightly apical to rs-m, cu-a slightly apical to Rs $+\mathrm{M}$, Rs moderately bowed forwards; hind wing with distal abscissa of $\mathrm{Cu}$ joining $\mathrm{Cu} \& \mathrm{cu}-\mathrm{a}$ close to junction with $\mathrm{M}$.

Meталома. Tergite 1 moderately slender, sparsely and shallowly punctate; tergite 2 and following densely punctate; apical margins of all tergites straight. Some other yellow species also sometimes have some punctures on tergite 2 (E. tombeaodiba), but the first tergite of the female is then distinctively stouter.

Male

Unknown.

\section{Distribution}

South Africa (KwaZulu-Natal).

Epirhyssa tombeaodiba sp. nov. urn:1sid:zoobank.org:act:134C55D0-CBC2-4788-B199-2197C7344475

Fig. 9

\section{Diagnosis}

Bright yellow overall with isolated dorsal black markings; wings hyaline, slightly infuscate apically; face rugulose-punctate, distinctly protruding dorsally; clypeus shallowly longitudinally strigose with a strong subapical median tubercle, ventral margin hardly produced laterally; frons smooth, with a weak mid-longitudinal carina reaching median ocellus; mesopleuron with epicnemial carina reaching level of mesopleural pit; subtegular ridge convex; fore wing with $2 \mathrm{~m}-\mathrm{cu}$ distinctly apical to rs-m; tergite 1 stout in female (male unknown); tergite 1 about smooth, following tergites more or less densely punctate; apical margins of all tergites straight. CT 2.8; ML 0.7; POL 1.3; OOL 1.3; $\mathrm{Fl}_{1} 4.0 ; \mathrm{Fl}_{15}$ 2.2; T1 1.2; OT 4.0.

\section{Differential diagnosis}

Bright yellow species with wings hyaline, otherwise characterized by the combination of the entirely punctate tergite 2, the weak mid-longitudinal carina on the frons and the stout tergite 1 . It is the only known yellow Epirhyssa species with both a distinctly sculptured clypeus and a stout tergite 1.

\section{Etymology}

Refers to Mrs Jackson's ambiguous marital status as reported by label data. In the Duala language, "tómbea ó dibá" means "to get married" for a woman.

\section{Type material}

\section{Holotype}

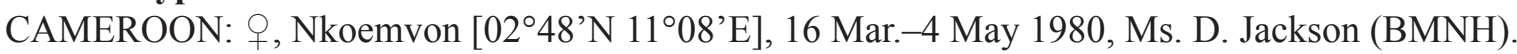




\section{Paratypes}

1 , same label data (BMNH); 1 ㅇ, same label data except: 30 Mar.-19 Apr. 1980 (BMNH); 1 + , same label data except: Korup 1981, Mrs D. Jackson (BMNH).
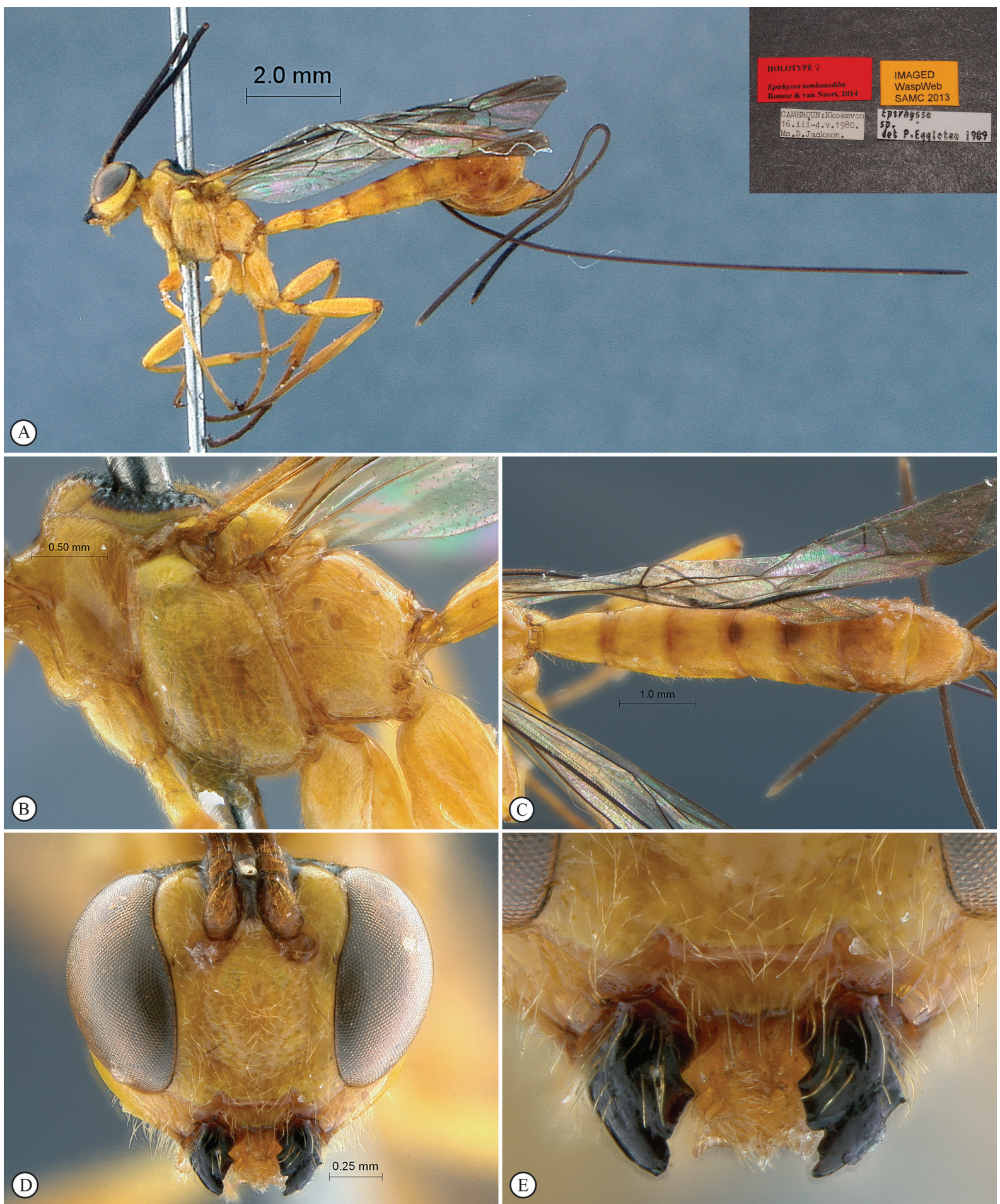

Fig. 9. Epirhyssa tombeaodiba sp. nov., holotype,, . A. Habitus, lateral view (inset: data labels). B. Mesosoma, lateral view. C. Metasoma, dorsal view. D. Head, anterior view. E. Mandibles, anterior view. 


\section{Description}

Female (4 specimens)

B 7.2-8.9; A 9.5; F 9.0-10.5. (holotype B: 8.0; A NA; F 9.9).

CoLOR. Bright yellow overall with black parts: mandible, ocellar area (macula connected to eye margin), a median spot on each mesoscutal lobe, scuto-scutellar groove, a mid-longitudinal macula of variable length on tergites 4-7; flagellum dark brown; flagellum and ovipositor sheath reddish-brown; wings hyaline, slightly infuscate apically, venation brown.

HEAD. Face subquadrate, rugulose-punctate, distinctly protruding dorsally; clypeus longitudinally strigose, with a strong subapical median lobe, ventral margin hardly produced laterally; mandible stout; frons, vertex and temple sparsely and shallowly punctate; inner margins of toruli expanded backwards into two converging weak carinae, carinae then fused into a mid-longitudinal carina reaching median ocellus; occipital carina mid-dorsally interrupted; antenna with at least 22 flagellomeres (no specimen with complete flagellum).

Mesosoma. Mesosoma shallowly and moderately densely punctate, but mesonotum deeply transversely striate and anterior half of pronotum smooth; epicnemial carina reaching level of mesopleural pit; apex of subtegular ridge convex, not flanged laterally; submetapleural carina slightly enlarged anteriorly, then evenly narrowed toward apex, strongly notched at anterior third in one paratype.

WINGS. Fore wing with $2 \mathrm{~m}$-cu distinctly apical to rs-m, cu-a barely apical to Rs\&M, and Rs moderately bowed forwards; hind wing with distal abscissa of $\mathrm{Cu}$ joining $\mathrm{Cu} \& \mathrm{cu}-\mathrm{a}$ shortly below junction with $\mathrm{M}$.

Metasoma. Tergite 1 moderately stout, nearly smooth; following tergites shallowly and more or less densely punctate, punctation progressively finer toward apex; apical margins of all tergites straight.

\section{Distribution}

Cameroon.

Epirhyssa uelensis Benoit, 1951

Fig. 10

\section{Diagnosis}

Bright yellow overall with isolated dorsal black markings; wings hyaline, slightly infuscate apically; face rugulose-punctate and moderately protruding dorsally; clypeus nearly smooth, with median subapical tubercle strong, ventral margin produced laterally; frons nearly smooth, with a mid-longitudinal carina reaching median ocellus and lateral curved carina toward lateral ocellus; antenna with 32-34 flagellomeres; mesopleuron with epicnemial carina reaching level of mesopleural pit; subtegular ridge concave, laterally flanged; fore wing with $2 \mathrm{~m}$-cu slightly apical to rs-m; tergite 1 stout in female, very slender in male; tergites 1-3 smooth, following tergites shallowly punctate with basal transverse striations; apical margins of tergites 3-6 moderately concave. CT 2.9; ML 0.6; POL 1.2; OOL 1.3; $\mathrm{Fl}_{1}$ $3.8 ; \mathrm{Fl}_{15} 2.2 ; \mathrm{FL}_{33} 0.9 ; \mathrm{T} 11.2-1.3 ; \mathrm{OT} 4.1$.

\section{Differential diagnosis}

A mostly bright yellow species with hyaline wings, otherwise characterized by the combination of the concave subtegular ridge, the mid-longitudinal carina on the frons and the stout tergite 1 of the female. The only other species with a concave and flanged subtegular ridge is E. gavinbroadi, in which the clypeus is distinctly punctate. 
ROUSSE P. \& VAN NOORT S., Review of Afrotropical Rhyssinae

\section{Material examined}

\section{Holotype}

DEMOCRATIC REPUBLIC OF CONGO: ' + Haut-Uele, Paulis [Isiro, $03^{\circ} 28^{\prime}$ N 2543'E], xii-1947, P.L.G. Benoit (MRAC).
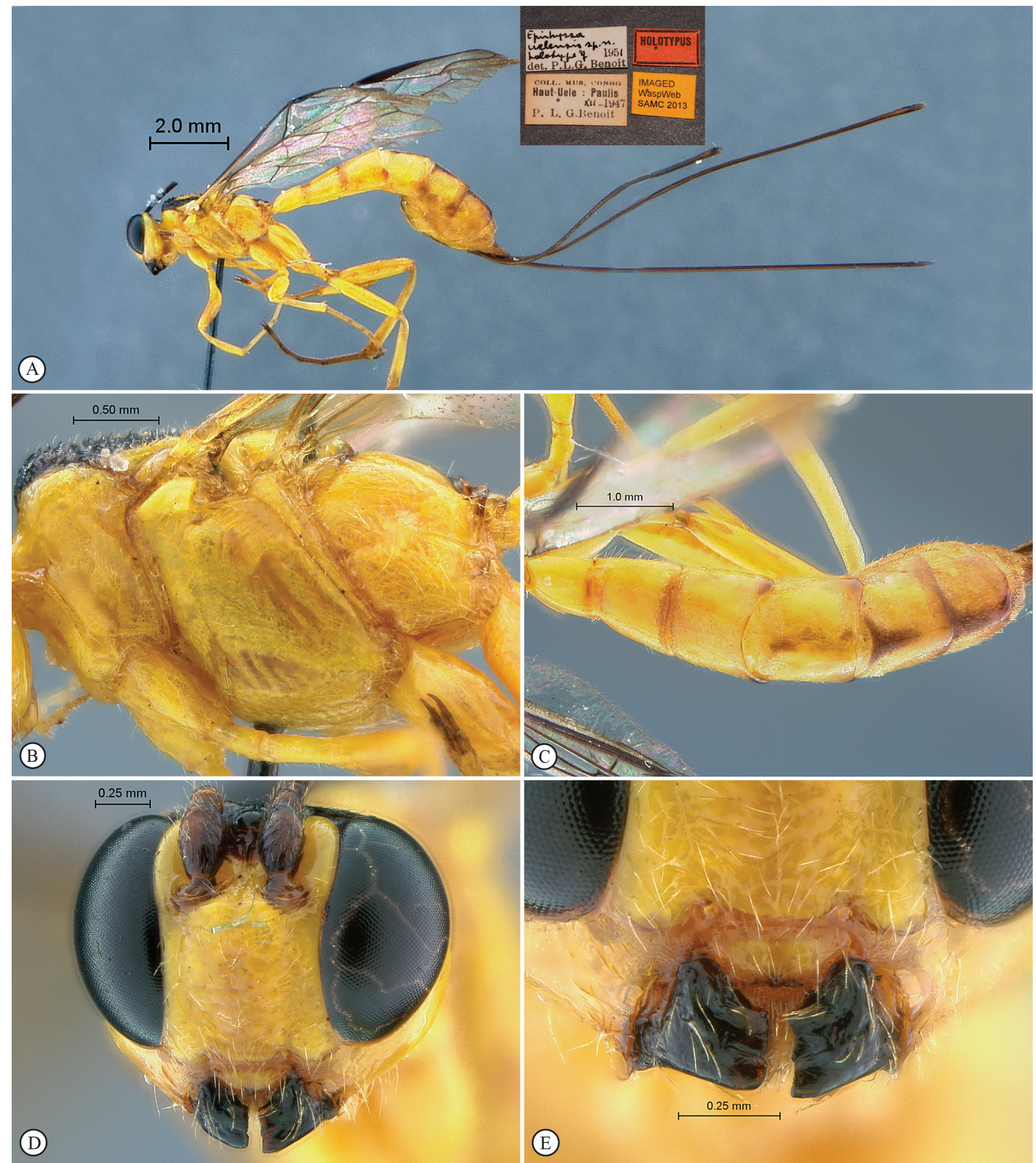

Fig. 10. Epirhyssa uelensis Benoit, 1951, holotype, ․ A. Habitus, lateral view (inset: data labels). B. Mesosoma, lateral view. C. Metasoma, dorsal view. D. Head, anterior view. E. Mandibles, anterior view. 
Paratype

DEMOCRATIC REPUBLIC OF CONGO: 1 ○ૈ, Bambesa, Jul. 1933, H.J. Bredo (MRAC).

\section{Other material}

CAMEROON: 1 , Nkoemvon, 30 Mar.-19 Apr. 1980, Ms. D. Jackson (BMNH); 2 ㅇ, same label data except 13 Jul.-4 Aug. 1980 (BMNH); 1 ㅇ, same label data except Oct.-Nov. 1980 (BMNH).

\section{Description}

Female (5 specimens)

B 10.4-12.8; A 9.1-12.0; F 8.6-11.5 (holotype B: 10.4; A 9.1; F 8.6).

CoLOR. Bright yellow overall, sometimes with infuscate to black mid-longitudinal stripes on tergites 5-7, and black markings: mandible, ocellar area (macula connected to eye margin), upper occiput and mesoscutum but lateral margins and a large central macula, sometimes apex of scutellum, basal margin and apex of propodeum; ovipositor sheath reddish testaceous; wings hyaline, weakly infuscate apically, venation brown.

HEAD. Face rugulose-punctate and moderately protruding dorsally; clypeus smoothly sculptured, with a strong subapical median tubercle, ventral margin moderately produced laterally and medially; mandible stout; frons nearly smooth with sparse fine punctures; inner margins of toruli expanded backwards into two converging weak carinae, carinae then fused into a mid-longitudinal carina reaching median ocellus; frons also with an additional lateral curved carina from posterior margin of torulus to next to lateral ocellus; vertex and temples sparsely punctate, inter-ocellar area somewhat rugose; occipital carina mid-dorsally evanescent; hypostomal carina strongly raised above mandibular base; antenna with 32-34 flagellomeres.

Mesosoma. Mesosoma shallowly and moderately densely punctate, but mesonotum deeply transversely striate and anterior half of pronotum smooth; epomia moderate; dorsal faint apex of epicnemial carina nearly reaching level of mesopleural pit; apex of subtegular ridge concave, weakly to distinctly flanged laterally; submetapleural carina slightly and evenly narrowed toward apex.

WINGS. Fore wing with $2 \mathrm{~m}-\mathrm{cu}$ slightly apical to rs-m, cu-a slightly apical to Rs+M, Rs strongly bowed forwards; hind wing with distal abscissa of $\mathrm{Cu}$ joining $\mathrm{Cu} \& \mathrm{cu}-\mathrm{a}$ close to junction with $\mathrm{M}$.

Metasoma. Tergite 1 stout and smooth, tergites 2-3 smooth, tergites 3-6 shallowly punctate with weak transverse striations basally; apical margins of tergites 3-6 moderately concave, others straight.

Male (1 specimen)

B 8.5; A 8.2; F 7.9 .

Similar to female but metasoma much slenderer (T1 2.0).

\section{Distribution}

Democratic Republic of Congo. New record: Cameroon. 


\section{Epirhyssa villemantae sp. nov. urn:Isid:zoobank.org:act:C701D367-2EF0-4A73-8D41-F8F5EDADAA21}

Fig. 11

\section{Diagnosis}

Head and pronotum yellowish-orange; remainder of mesosoma black; metasoma orange; wings blackish with a pale subapical patch; face sparsely punctate and moderately protruding dorsally; clypeus smooth, with median subapical tubercle moderate, ventral margin truncate; frons laterally smooth, medially transversely striate, with two submedian carinae diverging toward lateral ocelli; antenna with 36 flagellomeres; mesopleuron with epicnemial carina reaching level of mesopleural pit; subtegular ridge convex; fore wing with $2 \mathrm{~m}-\mathrm{cu}$ slightly apical to rs-m; tergite 1 stout in female (male unknown); tergites 1-3 smooth, following tergites moderately punctate with basal transverse striations; apical margins of all tergites straight. CT 2.0; ML 0.6; POL 1.3; OOL 1.6; $\mathrm{Fl}_{1} 3.6 ; \mathrm{Fl}_{15} 2.1 ; \mathrm{FL}_{33}$ 0.9; T1 1.3; OT 4.4.

\section{Differential diagnosis}

A species with unique color pattern, with most of mesosoma black, metasoma orange and wings blackish with a subapical light patch; otherwise characterized by the sparsely punctate face, the truncate ventral margin of the clypeus and the stout tergite 1 of the female.

\section{Etymology}

Dedicated to Claire Villemant, MNHN curator, hymenopterologist and ichneumonomaniac, adviser, teacher, supporter, coach and friend.

\section{Type material}

Holotype

NIGERIA: + , Ilorin Prov. [06 48’'N 05²18’E], 18 Jun. 192 [sic], De. G.W.S. Macfie, Pres. by Imp. Bur. Ent. 1921-129 (BMNH).

\section{Description}

Female (holotype)

B 17.1; A 13.1; F 13.1.

CoLor. Head and pronotum yellowish-orange with mandible and ocellar area black; remainder of mesosoma blackish testaceous; metasoma orange; fore leg and mid leg from tibia yellowish orange, remainder of legs blackish testaceous; antenna and ovipositor sheath brown; wings strongly infuscate but with large subapical and small mid-dorsal pale yellowish patches on fore wing.

HEAD. Face sparsely punctate, almost smooth laterally, and moderately protruding dorsally; clypeus smooth, with a moderate subapical median tubercle, ventral margin truncate; mandible stout; frons laterally smooth, medially transversely striate; inner margin of toruli expanded backwards into two weak sinuate submedian carinae, carinae then diverging and reaching lateral ocelli; frons also with an additional lateral curved carina from posterior margin of torulus to next to lateral ocellus; vertex and temples almost smooth, inter-ocellar area somewhat rugose; occipital carina mid-dorsally evanescent; hypostomal carina strongly raised above mandibular base; antenna with 36 flagellomeres.

Mesosoma. Mesosoma finely, sparsely and shallowly punctate, but mesonotum transversely striate and pronotum, speculum area and propodeum medially smooth; epomia very weak; dorsal faint apex of epicnemial carina reaching level of mesopleural pit; apex of subtegular ridge convex, not flanged laterally; submetapleural carina moderate and even all along. 

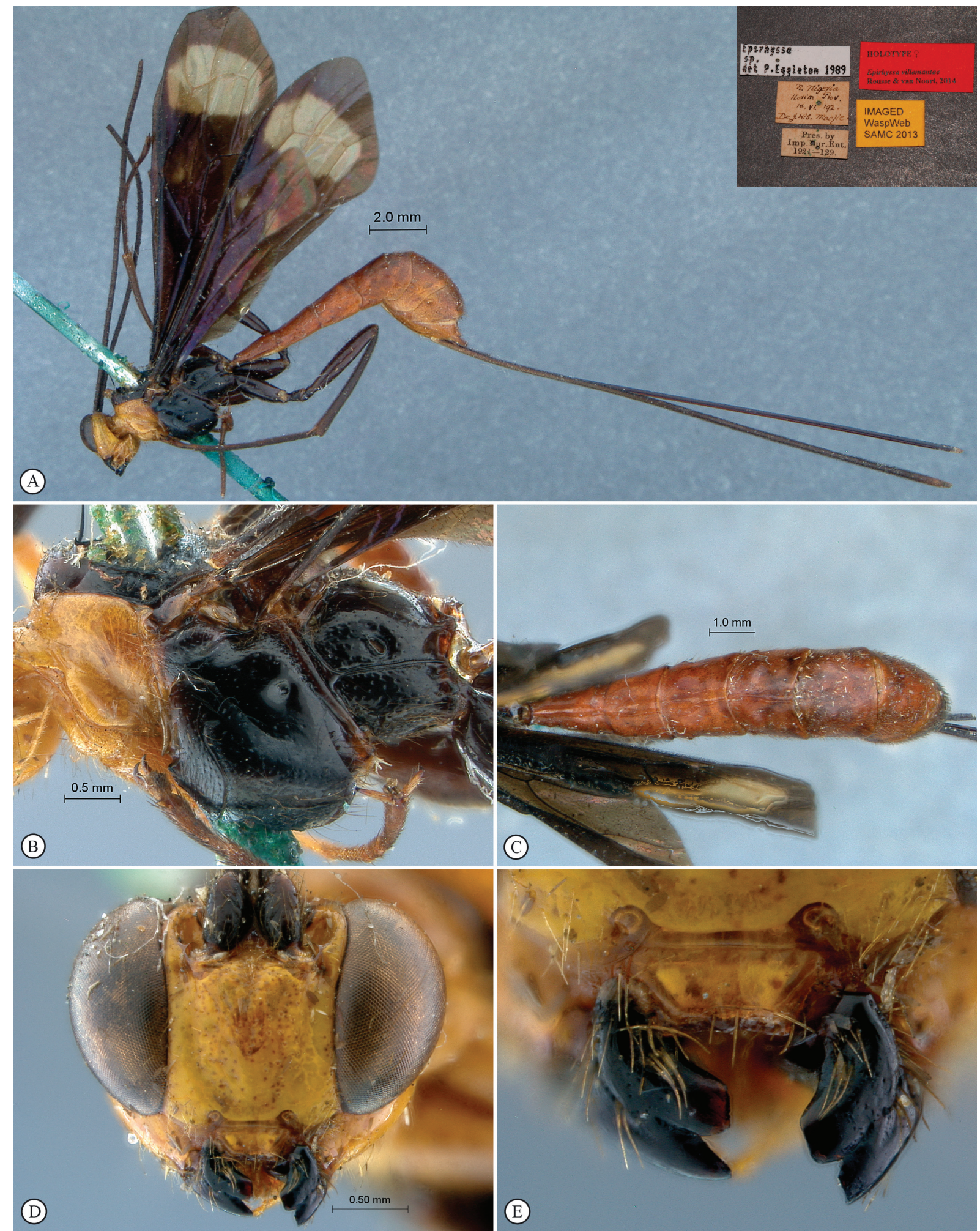

Fig. 11. Epirhyssa villemantae sp. nov., holotype, $q$. A. Habitus, lateral view (inset: data labels). B. Mesosoma, lateral view. C. Metasoma, dorsal view. D. Head, anterior view. E. Mandibles, anterior view. 
Wings. Fore wing with $2 \mathrm{~m}-\mathrm{cu}$ slightly apical to $\mathrm{rs}-\mathrm{m}, \mathrm{cu}-\mathrm{a}$ slightly apical to Rs+M, Rs moderately bowed forwards; hind wing with distal abscissa of $\mathrm{Cu}$ joining $\mathrm{Cu} \& \mathrm{cu}-\mathrm{a}$ at its anterior third, remote from junction with $\mathrm{M}$.

Metasoma. Tergite 1 moderately stout; tergites 1-3 smooth, following tergites moderately punctate with weak transverse basal striations; apical margins of all tergites straight.

\section{Male \\ Unknown.}

\section{Distribution}

Nigeria.

Genus Megarhyssa Ashmead, 1900

Thalessa Holmgren, 1859: 122.

Megalorhyssa Shulz, 1906: 115.

Eurhyssa Derksen, 1941: 721.

\section{Diagnosis (updated from Townes 1969)}

Large to very large insects (fore wing length 10-30 mm); clypeus small, transversely rectangular, ventral margin laterally and sometimes medially bluntly produced; occipital and hypostomal carinae joining above mandible base; mandibular teeth subequal, lower tooth pointed and upper tooth more or less chisel shaped; propodeum of moderate length, without carina dorsally but pleural carina distinct; fore wing with areolet closed except in occasional dwarf males, receiving $2 \mathrm{~m}-\mathrm{cu}$ within its apical half, pterostigma about 5.5x longer than wide; hind wing with distal abscissa of $\mathrm{Cu}$ present, joining $\mathrm{Cu} \& \mathrm{cu}-\mathrm{a}$ near or at junction with $\mathrm{M}$; mid trochantellus with a ventral longitudinal ridge; tarsal claws simple, large; tergite 1 fused with its sternite and without glymma; tergites 3-6 almost smooth to finely and sparsely punctate and with isolated aciculate areas; female with sternites 2-4 each with a pair of tubercles near anterior margin, and with an apical truncate horn-like process on last tergite; male with metasoma strongly depressed, gonosquama lanceolate, strongly depressed, with a sharp piliferous groove along inner lower margin and a short subapical piliferous groove on outer face.

Species richness and distribution (Gauld 1984; Yu et al. 2012)

Megarhyssa is mostly a Holarctic and Oriental genus, with one species introduced into Australia and New Zealand for biocontrol purposes, and a single species reported from the Afrotropical Region.

Megarhyssa babaulti Seyrig, 1937

Fig. 12

Megarhyssa babaulti kapangaensis Seyrig, 1937: 116.

Megarhyssa babaulti kapangaensis var. rubra Benoit, 1951: 385.

Megarhyssa babaulti kapangaensis var. rubrerrima Benoit, 1951: 385.

\section{Diagnosis}

Head orange with a black part of variable extent; mesosoma orange, posterior third sometimes dark brown; metasoma mostly black with pale yellow or orange markings of variable extent; flagellum twocolored, basally black and apically orange; wings blackish with lighter patch of variable extent; face moderately punctate to smooth, flat; clypeus smooth, with median subapical tubercle weak, ventral margin strongly produced laterally; frons smooth with a pair of submedian carinae diverging toward 
lateral ocelli; epicnemial carina laterally absent; subtegular ridge convex; fore wing with areolet strongly petiolate, receiving $2 \mathrm{~m}-\mathrm{cu}$ at its distal apex, opposite $3 \mathrm{rs}-\mathrm{m}$; tergite 1 very stout; tergites $1-4$ smooth or mostly so, following tergites finely and densely punctate; apical margins of tergites 3-5 strongly concave. CT 3.4; ML 0.6; POL 1.2; OOL 1.7; $\mathrm{Fl}_{1} 4.4 ; \mathrm{Fl}_{15}$ 2.3; $\mathrm{Fl}_{39} 1.0$; $\mathrm{T} 1$ 1.1; OT 4.8.

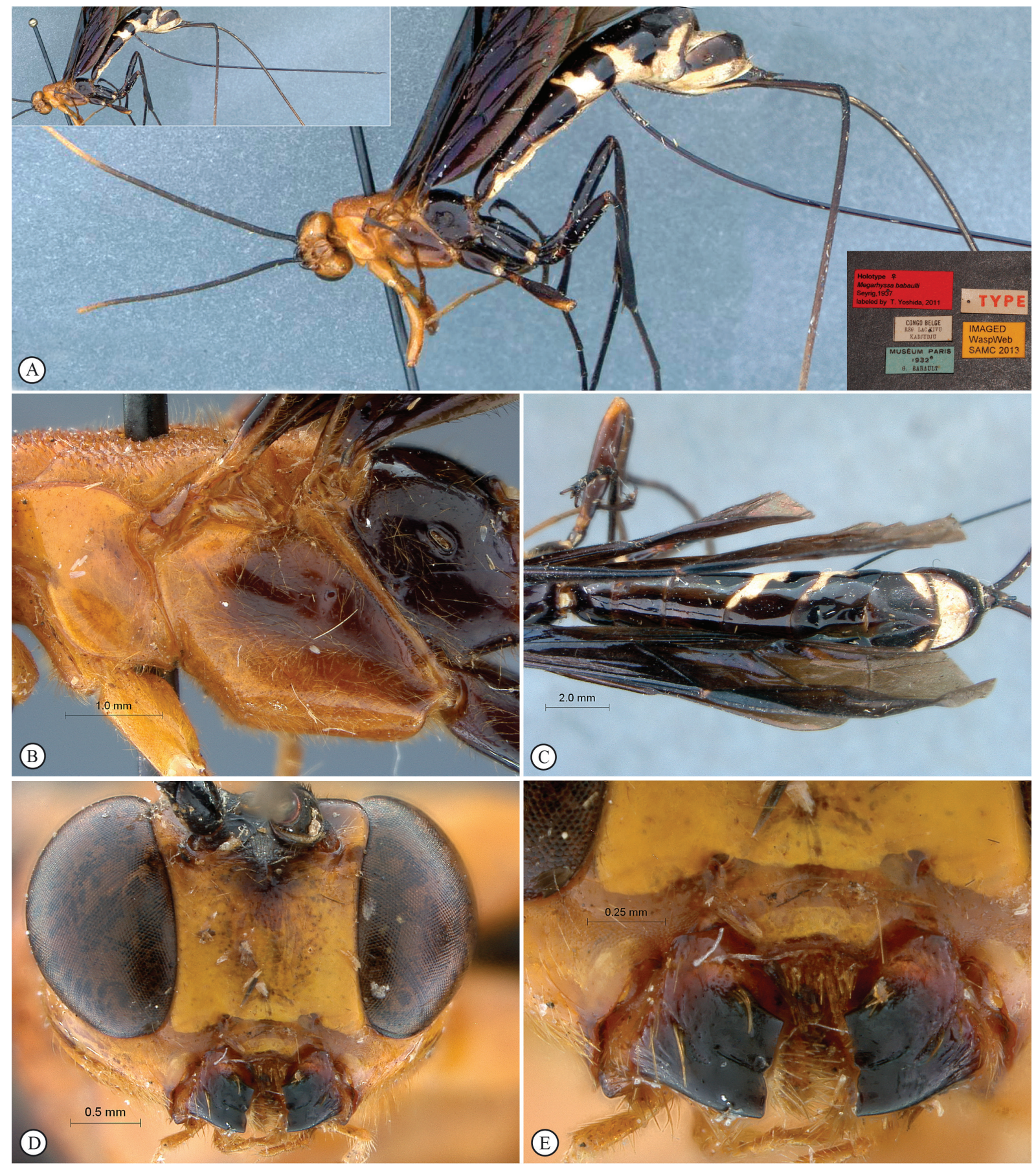

Fig. 12. Megarhyssa babaulti Seyrig, 1937, holotype, $q$. A. Habitus, lateral view (inset: data labels). B. Mesosoma, lateral view. C. Metasoma, dorsal view. D. Head, anterior view. E. Mandibles, anterior view. 


\section{Material examined}

\section{Holotype}

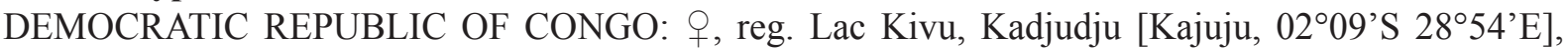
1932, G. Babault, MNHN EY8831.

\section{Description}

Female (holotype)

B 22.1; A 15.5; F 18.

CoLOR. Head orange with isolated black parts to almost entirely black; antenna basally black, fading to orange from flagellomere 12; mesosoma orange, posterior third varying from orange to entirely black; legs orange with mid and fore legs variably orange to dark brown; metasoma black with tergites 1-3 varying from orange to black, tergite 4 and following largely pale yellow laterally, sternites pale yellow; ovipositor sheath black, apical half fading to reddish-orange; wings blackish with lighter yellowish parts of variable extension (color variation: Seyrig 1937; Benoit 1951).

HEAD. Face flat, laterally smooth, medially moderately punctate; clypeus smooth, with a weak median subapical tubercle, ventral margin strongly produced laterally; upper head almost smooth; frons with a pair of weak submedian carinae, carinae diverging below median ocellus, inner margins of toruli hardly produced backwards; occipital carina complete, mid-dorsally weak; antenna with 40 flagellomeres.

Mesosoma. Mesosoma finely and moderately densely punctate, but mesonotum deeply transversely striate and anterior half of pronotum smooth; epomia indistinct; epicnemial carina absent except for a faint ventral remnant; apex of subtegular ridge convex, not flanged laterally; submetapleural carina barely expanded anteriorly and evenly narrowed toward apex.

WINGS. Fore wing with areolet strongly petiolate, receiving $2 \mathrm{~m}-\mathrm{cu}$ at its apex, cu-a strongly apical to Rs\&M, Rs strongly bowed forwards; hind wing with distal abscissa of $\mathrm{Cu}$ joining $\mathrm{Cu} \& \mathrm{cu}-\mathrm{a}$ shortly above middle of $\mathrm{Cu} \& \mathrm{cu}-\mathrm{a}$.

Metasoma. Tergite 1 stout, nearly as long as apically wide; tergites 1-3 quite smooth, tergite 4 smooth with some fine punctures basally, following tergites finely and densely punctate; apical margins of tergites $3-5$ strongly concave.

\section{Male \\ Unknown.}

\section{Distribution}

Democratic Republic of Congo.

\section{Discussion}

We face here an apparent paradoxical observation: despite the historical general interest they have received and their expected high diversity in the tropics, very few species of Rhyssinae have been described in Africa, and the African and European museums house only scarce, undetermined material. Discussing the zoogeographical history of Epirhyssa in the Neotropical region, Porter $(1978,1982)$ showed that their abundance, distribution and phenology are strongly related to the humidity level: dry periods and arid areas are major ecological obstacles for Rhyssinae, hence they are expected to be highly diversified in lowland tropical humid forests. Nevertheless, the collection efforts carried out by the Iziko South African Museum in Gabon, Uganda, Central African Republic and South Africa 
Table 1. Summary of the main collecting efforts by Simon van Noort of SAMC in Africa over the last 22 years (MTM: Malaise trap months; YPTM: yellow pan trap months).

\begin{tabular}{|l|c|c|c|c|c|}
\hline Country & Year(s) & MTM & YPTM & Sweeps & $\begin{array}{c}\text { Rhyssinae } \\
\text { collected }\end{array}$ \\
\hline Gabon & 2000 & 3 & 18 & 3000 & 0 \\
\hline Central African Republic & 2001 & 8 & 6 & 6000 & 2 \\
\hline Uganda & $2005 \& 2008$ & 12 & 71 & Not quantified & 0 \\
\hline South Africa & $1992-$ present & $c .2000$ & $c .4500$ & $c .30000$ & 0 \\
\hline
\end{tabular}

(Table 1) produced only two specimens, despite the fact that a large proportion of the central African sampling took place in lowland rainforest. On the other hand, examination of the mere 15 undetermined specimens gathered for this study revealed that half of them belonged to five new species, four of them being singletons.

Thus, Rhyssinae appear very rare though greatly diversified in the Afrotropical region. Their rarity may be explained by ecological hypotheses. Rhyssinae are indeed known to parasitize primarily Siricidae and Xiphydriidae in the Northern Hemisphere (Yu et al. 2012), while these families are poorly represented in the tropics. Virtually nothing is known about the ecology of Epirhyssa, but as some Holarctic Rhyssinae are also known to exploit Cerambycidae, they have been hypothesized to develop mostly on woodboring coleopteran larvae (Gauld 1991). This ecological niche, however, is also exploited by other taxa: Braconinae, for example, have been diversifying in Africa for a long time, and one plausible hypothesis is that the competition was disadvantageous for Rhyssinae (G. Broad, pers. comm.).

Somewhat contradictory with his own observations, Porter $(1978,1982)$ stated that the largest lowland rainforest of the world in the Amazon Basin was rather depleted of Rhyssinae. Following their own collection efforts in this region, Sääksjärvi et al. (2004) and Veijalainen et al. (2013), however, showed that Porter's biogeographical assumptions were mainly influenced by sampling bias: intensive local collection efforts are needed to uncover most of the diversity of Rhyssinae and other hymenopteran groups. Sääksjärvi et al. (2004) report a sampling effort of 185 Malaise trap months resulting in 12 new species. These figures of return relative to sampling effort appear similar to ours from tropical areas of Africa. We predict that most of the Afrotropical diversity of Rhyssinae has still to be discovered, but intensive efforts of long-term sampling are required to unveil them.

\section{Acknowledgments}

We are grateful to the curators of the above mentioned museums for loaning specimens, and once again to Gavin Broad for his advice. Simon van Noort was funded by South African NRF (National Research Foundation) grants: GUN 2068865; GUN 61497; GUN 79004; GUN 79211; GUN 81139. Part of the South African field work conducted by SvN was funded by the National Science Foundation under PlatyPBI grant No. DEB-0614764 to N.F. Johnson and A.D. Austin. Pascal Rousse was funded by SABI (South African Biodiversity Initiative) NRF post-doctoral fellowship GUN 81609, a Claude Leon Foundation post-doctoral fellowship, and Société Entomologique de France (Bourse Germaine Cousin). Cape Nature, the Eastern Cape Department of Environmental Affairs and the Northern Cape Department of Nature and Environmental Conservation provided collecting permits for South Africa. Fieldwork in Gabon was funded by the World Bank through WWF-US and WWF-CARPO. Collecting and export permits were granted by Emile Mamfoumbi Kombila, Directeur de la Faune et de la Chasse, Libreville. The Ugandan Wildlife Authority and UNCST provided permits to conduct research in Uganda. Field work in Central African Republic was supported by WWF-US and WWF-CARPO. The Ministers of Water, Forests and the Environment and the High Commissioners for tertiary Education and Research of the Central African Republic granted permission to carry out the inventory survey and to export the 
specimens as part of the WWF-US CAR field expedition conducted in 2001. Disclaimer: the attributed names referring to historical personages are purely functional: neither of the authors approves, nor supports any aspect of the atypical policy of King Shaka Zulu nor any other monarch of the $19^{\text {th }}$ Century.

\section{References}

Baltazar C.R. 1961. The Philippine Pimplini, Poeminiini, Rhyssini, and Xoridini (Hymenoptera, Ichneumonidae, Pimplinae). Monographs of the National Institute of Science and Technology 7: 1-130.

Benoit P.L.G. 1951. Les Rhyssini éthiopiens (Pimplinae - Ichneumonidae). Revue de Zoologie et de Botanique Africaines 44: 382-385.

Benoit P.L.G. 1952. Notes Ichneumonologiques Africaines II. Revue de Zoologie et de Botanique Africaines 46: 51-59.

Buffington M.L., Burks R. \& McNeil L. 2005. Advanced Techniques for Imaging Parasitic Hymenoptera. American Entomologist 51: 50-54.

Buffington M.L. \& Gates M. 2009. Advanced imaging techniques II: using a compound microscope for photographing point-mount specimens. American Entomologist 54: 222-224.

Gauld I.D. 1984. An Introduction to the Ichneumonidae of Australia. British Museum of Natural History, London, UK.

Gauld I.D. 1991. The Ichneumonidae of Costa Rica, 1. Memoirs of the American Entomological Institute 47: $1-589$.

Gauld I.D., Wahl D.B., Bradshaw K., Hanson P. \& Ward S. 1997. The Ichneumonidae of Costa Rica, 2. Memoirs of the American Entomological Institute 57: 1-485.

Hanson H.S. 1939. Ecological notes on the Sirex wood wasps and their parasites. Bulletin of Entomological Research 30: 27-76. http://dx.doi.org/10.1017/S0007485300004399

Horstmann K. 2002. Revisionen von Schlupfwespen-Arten VI (Hymenoptera: Ichneumonidae). Mitteilungen der Münchener Entomologischen Gesellschaft 92: 79-91.

Jansson R., Rodríguez-Castañeda G. \& Harding L.E. 2013. What can multiple phylogenies say about the latitudinal diversity gradient? A new look at the tropical conservatism, out-of-the-tropics and diversification rate hypotheses. Evolution 7: 1741-1755. http://dx.doi.org/10.1111/evo.12089

Kamath M.K. \& Gupta V.K. 1972. Ichneumonologia Orientalis, Part II. The Tribe Rhyssini (Hymenoptera: Ichneumonidae). Oriental Insects Monographs 2: 1-300.

Kasparyan D.R. \& Khalaim A.I. 2007. Pimplinae, Tryphoninae, Eucerotinae, Xoridinae, Agriotypinae, Lycorininae, Neorhacodinae, Ctenopelmatinae, Phrudinae, Ophioninae, Acaenitinae, Collyriinae, Mesochorinae. Key to the insects of Russia Far East. Vol. IV. Neuropteroidea, Mecoptera, Hymenoptera 5. Academy of Sciences, Saint-Petersburg.

Kerr P.H., Fischer E.M. \& Buffington M.L. 2008. Dome lighting for insect imaging under a microscope. American Entomologist 54: 198-200.

Porter C.C. 1978. A revision of the genus Epirhyssa (Hymenoptera, Ichneumonidae). Studia Entomologica 20: 297-318.

Porter C.C. 1982. Systematics and zoogeography of the neotropic genus Epirhyssa (Hymenoptera: Ichneumonidae). National Geography Society Research Reports 14: 513-522.

Quicke D.L.J. 2012. We know too little about parasitoid wasp distributions to draw any conclusions about latitudinal trends in species richness, body size and biology. PLoS One 7: 1-9. http://dx.doi. org/10.1371/journal.pone.0032101 
Sääksjärvi I.E., Haataja S., Neuvonen S., Gauld I.D., Jussila R., Salo J. \& Burgos A.M. 2004. High local species richness of parasitic wasps (Hymenoptera: Ichneumonidae; Pimplinae and Rhyssinae) from the lowland rainforests of Peruvian Amazonia. Ecological Entomology 29: 735-743. http:// dx.doi.org/10.1111/j.0307-6946.2004.00656.x

Seyrig A. 1937. Sur les Rhyssini de la faune éthiopienne (Hym. Ichneumonidae). Revue de Zoologie et de Botanique Africaines 30: 112-116.

Sheng M.-L. \& Sun S.-P. 2010. Parasitic Ichneumonids on Woodborers in China (Hymenoptera: Ichneumonidae). Science Press, Beijing, China.

Spradbery J.P. 1968. A technique for artificially culturing ichneumonid parasites of woodwasps (Hymenoptera: Siricidae). Entomologia Experimentalis et Applicata 11: 257-260.

Spradbery J.P. 1970. Host finding by Rhyssa persuasoria (L.), an ichneumonid parasite of siricid woodwasps. Animal Behaviour 18: 103-114. http://dx.doi.org/10.1016/0003-3472(70)90077-1

Townes H.K. 1969. The genera of Ichneumonidae, part 1. Ephialtinae to Agriotypinae. Memoirs of the American Entomological Institute 11: 1-300.

Townes H.K. 1975. The parasitic Hymenoptera with the longest ovipositors, with descriptions of two new Ichneumonidae. Entomological News 86: 123-127.

Townes H.K., Townes M., Walley G.S., Walkley L., Habeck D. \& Townes G. 1960. Ichneumon-flies of America north of Mexico: 2. Subfamilies Ephialtinae, Xoridinae, Acaenitinae. United States National Museum Bulletin 216: 1-676. http://www.biodiversitylibrary.org/item/32635\#page/5/mode/1up

Veijalainen A., Sääksjärvi I.E., Erwin T.L., Gómez I.C. \& Longino J.T. 2013. Subfamily composition of Ichneumonidae (Hymenoptera) from western Amazonia: insights into diversity of tropical parasitoid wasps. Insect Conservation and Diversity 6: 28-37. http://dx.doi.org/10.1111/j.1752-4598.2012.00185.x

Wahl D.B. \& Gauld I.D. 1998. The cladistics and higher classification of the Pimpliformes (Hymenoptera: Ichneumonidae). Systematic Entomology23:265-298.http://dx.doi.org/10.1046/j.1365-3113.1998.00057.x

Wahl D.B. \& Sharkey M.J. 1993. Chapter 10. Superfamily Ichneumonoidea. In: Goulet H. \& Huber J.T. (eds) Hymenoptera of the World: An Identification Guide to Families: 359-509. Agriculture Canada, Ottawa.

Yu D.S.K., Van Achterberg C. \& Horstmann K. 2012. Taxapad 2012, Ichneumonoidea 2011. Database on flash-drive. www.taxapad.com, Ottawa.

Manuscript received: 14 February 2014

Manuscript accepted: 10 June 2014

Published on: 25 July 2014

Topic editor: Koen Martens

Desk editor: Kristiaan Hoedemakers

Printed versions of all papers are also deposited in the libraries of the institutes that are members of the EJT consortium: Muséum National d'Histoire Naturelle, Paris, France; Botanic Garden Meise, Belgium; Royal Museum for Central Africa, Tervuren, Belgium; Natural History Museum, London, United Kingdom; Royal Belgian Institute of Natural Sciences, Brussels, Belgium; Natural History Museum of Denmark, Copenhagen, Denmark. 